\title{
Labyrinthe
}

26 | 2007 (1)

Penser par extraordinaire

\section{Penser par extraordinaire}

Marc Aymes, Charles Ruelle, Élodie Cassan, Déborah Cohen, Benoît Fliche, Héloïse Hermant, Bérengère Hurand et Laurence Marie

\section{(2) OpenEdition}

\section{Journals}

Édition électronique

URL : http://journals.openedition.org/labyrinthe/4153

DOI : $10.4000 /$ labyrinthe.4153

ISSN : 1950-6031

Éditeur

Hermann

Édition imprimée

Date de publication : 15 mars 2007

Pagination : 11-76

ISBN : 978-2-9526131-3-2

Référence électronique

Marc Aymes, Charles Ruelle, Élodie Cassan, Déborah Cohen, Benoît Fliche, Héloïse Hermant,

Bérengère Hurand et Laurence Marie, «Penser par extraordinaire », Labyrinthe [En ligne], 26 | 2007 (1), mis en ligne le 01 avril 2009, consulté le 03 mai 2019. URL : http://journals.openedition.org/ labyrinthe/4153; DOI : 10.4000/labyrinthe.4153 


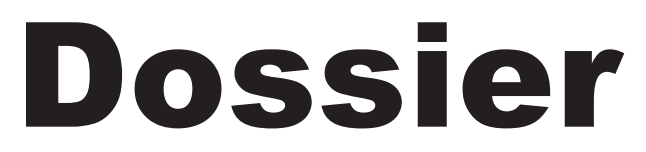

\section{Penser par extraordinaire}

Coordonné

par Marc Aymes et Charles Ruelle 



\title{
Penser par extraordinaire
}

\section{Ont participé à ce dossier}

\author{
Marc AYMES \\ marc.aymes@voila.fr \\ Élodie CASSAN \\ elodiecassan@yahoo.com \\ Déborah COHEN \\ cohen.deborah@free.fr \\ Benoît FLICHE \\ fliche@ehess.fr \\ Héloïse Hermant \\ heloise.hermant@wanadoo.fr \\ Bérengère HuRAND \\ berhurand@yahoo.fr \\ Laurence MARIE \\ lau.marie@gmail.com \\ Charles Ruelle \\ charles.ruelle01@gmail.com
}





\title{
SORTIR DU PIÈGE
}

\author{
(Witold Gombrowicz, Journal, 1963, à propos de Cosmos)
}

Dans l'infinité des phénomènes qui se passent autour de moi, j'en isole un. J'aperçois, par exemple, un cendrier sur ma table (le reste s'efface dans l'ombre).

Si cette perception se justifie (par exemple, j'ai remarqué le cendrier parce que je veux y jeter la cendre de ma cigarette), tout est parfait.

Si j'ai aperçu le cendrier par hasard et ne reviens pas là-dessus, tout va bien aussi.

Mais si, après avoir remarqué ce phénomène sans but précis, vous y revenez, malheur! Pourquoi y êtes-vous revenu, s'il est sans signification? Ah ah! ainsi il signifiait quelque chose pour vous, puisque vous y êtes revenu? Voilà comment, par le simple fait que vous vous êtes concentré sans raison une seconde de trop sur ce phénomène, la chose commence à être un peu à part, à devenir chargée de sens...

Non, non! (vous vous défendez) c'est un cendrier ordinaire.

Ordinaire? Alors pourquoi vous en défendez-vous, s'il est vraiment ordinaire?

Voilà comment un phénomène devient une obsession...

La réalité serait-elle, dans son essence, obsessionnelle? Étant donné que nous construisons nos mondes en associant des phénomènes, je ne serais pas surpris qu'au tout début des temps il y ait eu une association gratuite répétée fixant une direction dans le chaos et instaurant un ordre.

Il y a dans la conscience quelque chose qui en fait un piège pour ellemême.

\section{L'ORDINAIRE : PLATITUDE ET SCEPTICISME?}

Penser l'ordinaire comporte des risques. Philippe Artières nous en a récemment apporté une nouvelle preuve. Son dernier ouvrage, Rêves 
d'histoire ${ }^{1}$, exemplifie le risque toujours proche de ramener l'ordinaire à l'absence de définition (on parlera même d' «infra-ordinaire», sans expliciter d'où surgit le besoin de ce superlatif déflationniste) et à un passe-droit pour quitter en douce les rives de l'exigence scientifique, au nom de l'émotion, d'un Moi envahissant, surgissant sans cesse par le biais de ces «notations autobiographiques qui font partie intégrante de [la] démarche». Dans un ouvrage qui se veut hors des sentiers de la spécialisation, butinant çà et là les douces envies d'une «histoire à faire», on ne pense l'ordinaire qu'au prix de l'oubli volontaire des contraintes scientifiques (sources disponibles, littérature secondaire, réalisme de la compatibilité des comparaisons proposées qui virent ici à l'hétéroclite). On se trouve alors devant des lubies, qui pourrait être celles de n'importe quel historien, voire de tout curieux parcourant le monde. Artières envisage de faire un jour l'histoire des cloisons, des ceintures, s'amuse du possible rapprochement entre Albertine Sarrazin et Thérèse de Lisieux, ou de l'histoire encore à faire d'une région à partir des souches d'arbre. On peut certes entrevoir un enjeu politico-social derrière le désir d'aller à l'ordinaire. Mais celui-ci est ambigu: s'il s'accompagne de l'idée que l'ordinaire se joue dans la proximité, dans l'évidence et l'abandon du scientifique, il est aussi méprisant. Ainsi chez Artières la volonté proclamée de «rapprocher l'histoire de nos contemporains» ne peut-elle que choquer quand on constate ensuite qu'elle s'accompagne d'une sorte de mépris à l'encontre de «nombre de lecteurs » (sûrement très «ordinaires») épris du genre biographique contre lequel l'auteur s'échauffe en considérant qu'il s'agit du «pire des genres historiques » - au moment où il ne nous offre au fond rien d'autre que son autobiographie subjective.

D'une certaine manière, le sociologue Philippe Corcuff, dans une analyse des rêves romanesques de l'hérö̈ne de la série Ally McBeal et de deux de ses spectatrices, est victime de la même difficulté tendue par l'ordinaire ${ }^{2}$. Comme chez Artières, tout se passe ici comme si l'ordinaire autorisait un départ des règles de scientificité. Malgré la place du mot «enquête» dans le titre même choisi par l'auteur de l'article, on répugnera à appeler tel un propos appuyé sur deux entretiens aux conditions mal élucidées, conceptualisés comme relevant du «potentiellement poli-

1. Rêves d'histoire. Pour une histoire de l'ordinaire, Les prairies ordinaires, 2006.

2. Philippe Corcuff, «De l'imaginaire utopique dans les cultures ordinaires. Pistes à partir d'une enquête sur la série télévisée Ally McBeal», dans Claude Gautier et Sandra Laugier (dir.), L'Ordinaire et le politique, Paris, PUF, 2006, p.71-83. 
tisable» (sans qu'aucun indice convaincant n'en soit fourni). On tombe décidément ici encore dans le risque du populisme, pourtant rappelé par l'auteur lui-même.

La solution sera-t-elle dès lors de se tourner vers l'extraordinaire?

Contre cet ordinaire ininterrogé, réduit au quotidien, la plupart des participants du colloque «L'ordinaire et le politique», dont les actes ont été rassemblés par Claude Gautier et Sandra Laugier, sont au contraire partis de l'idée d'une «inquiétante étrangeté de l'ordinaire ${ }^{1} »$. Sans être l'Autre, minable à dépasser par le geste philosophique, l'ordinaire, nous met-on en garde, ne saurait non plus être le lieu d'une réappropriation facile du monde.

Partant de la tradition wittgensteinienne d'analyse du langage ordinaire, plusieurs auteurs de ce recueil posent la question du scepticisme. D'emblée Leila Raïd nous confronte à l'opacité du familier, au risque de la tromperie de l'ordinaire. Pour autant, il ne s'agit pas de dissiper cette opacité par l'imposition de savoirs externes: si l'ordinaire est trompeur, il est aussi «un lieu réflexif par nature», et l'analyse peut, sans faire système mais plutôt de manière idiosyncrasique, restituer un ordre des usages communs de la langue et des actions. Sandra Laugier, s'appuyant sur Stanley Cavell, reprend pour ainsi dire l'inquiétude à ce point précis, celui du risque de l'idiosyncrasie: "Comment sais-je ce que nous voulons dire?», comment vouloir dire ce que nous disons? L'analyse du langage ordinaire n'est pas suffisante ici à résoudre la question sceptique, elle la porte au contraire, car il n'y a pas accord du nous sur le langage mais en lui: nous ne sommes pas les acteurs d'un simple pacte, les auteurs d'une convention, bien plutôt sommes-nous pris dans le langage, dans la voix, dans le corps. Sortir du scepticisme, ce serait alors un acte de reconnaissance et d'acceptation de cette emprise de l'autre, du corps, de notre condition humaine - un acte profondément démocratique. C'est dans cette trame, et en critique de l'ordinaire wittgensteinien, que s'inscrit Élise Domenach pour penser l'acte sceptique comme mettant en cause l'ordinaire lui-même, l'humanité elle-même, par «l'effort fou et spécifiquement humain », lié à nos passions vitales, «pour nier l'indéniable», notamment l'indéniable du corps présenté comme limite à la connaissance. Ici aussi, appel est fait à un acte de reconnaissance: reconnaissance du monde ordinaire comme union d'âme et de corps, plutôt

1. Claude Gautier et Sandra Laugier (dir.), op. cit., p. 23. 
que connaissance; admiration plutôt qu'étonnement. La force d'appel à l'universel dans l'analyse de l'ordinaire est ici sans détour.

\section{THÉORISER L'EXTRAORDINAIRE?}

La conception classique de la vraisemblance à respecter au théâtre est fondée sur l'exclusion de l'extraordinaire: le dramaturge et, partant, l'acteur ne doivent pas contrevenir aux attentes du spectateur. L'ordinaire de la règle est privilégié, afin d'éviter toute surprise risquant de briser l'illusion mimétique. La déclamation se définit alors conformément à ce dessein: calquée sur les règles de l'action oratoire formalisées par Cicéron et Quintilien, elle privilégie l'expression vraisemblable sur l'expression vraie, et exclut toute singularité en imposant la répétition de gestes préétablis.

Cette vision esthétique change au milieu du XVIII ${ }^{\mathrm{e}}$ siècle. La crudité des représentations montrées en Angleterre excerce une fascination qui témoigne de l'attrait croissant pour le spectaculaire et d'où émerge une esthétique de la surprise, fondée sur une rupture de la doxa provoquée par la survenue d'incidents et/ou de comportements scéniques inattendus et singuliers. La transmission à l'identique, d'une génération à l'autre, de codes de jeu immuables se voit dès lors interrompue au profit de la valorisation de styles originaux, nourris par l'interprétation personnelle donnée par l'acteur à son rôle.

Les traités français et anglais sur le jeu du comédien publiés au milieu du XVIII ${ }^{\mathrm{e}}$ siècle prennent acte de cette demande de spectaculaire qui fait vaciller les fondements théoriques légitimant les règles du classicisme. Le Français Rémond de Sainte Albine est ainsi le premier, en 1747, à s'interroger sur les coulisses de la représentation théâtrale au sein d'un ouvrage traitant exclusivement du jeu: Le Comédien. Le texte est adapté en anglais dès 1750 par John Hill sous le titre The Actor, qui est à son tour librement retraduit en français, en 1769, par Antoine Fabio Sticotti (Garrick ou les acteurs anglais), contre lequel Denis Diderot écrit le Paradoxe sur le comédien dans les années 1770.

Quel peut bien être l'enjeu de cette circulation d'un même texte de part et d'autre de la Manche? Il s'agit rien moins que d'ouvrir un espace à la spontanéité dans le jeu, de dégager celui-ci de l'emprise de l'actio. 


\section{Penser par extraordinaire}

Est promu un nouveau style de jeu dit «sublime», préféré au jeu «parfait» à l'horizon du spectacle déclamatoire ${ }^{1}$. L'acteur sublime, identifié à son personnage, est décrit comme la proie d'élans incontrôlés qui transforment la représentation en une succession discontinue d'instants frappants. Chaque représentation devient irréductiblement unique, à l'image d'une nature vue comme mouvante et irrégulière. Le physique et le jeu irréguliers fondent une esthétique de l'écart productrice d'une surprise sans cesse renouvelée qui vise à provoquer de «violentes secousses ${ }^{2} »$ et à «déchirer les entrailles ${ }^{3} »$ du spectateur.

Rendre compte des intermittences du sublime sans en altérer la spécificité pose la question de sa théorisation par les traités de jeu. Prenant les soubresauts de cette nouvelle expression théâtrale comme point de départ méthodologique, les auteurs tentent en effet paradoxalement de codifier ce qui, par définition, échappe à la règle: ils font entrer de force dans les exposés systématiques du traité ce qui fait «jeu», ce qui, tel un levier, fait basculer l'édifice rhétorique. Pour ce faire, ils appuient leur analyse sur les instants d'exception offerts au public par des acteurs hors du commun. Ainsi les spectateurs chanceux ont-il pu voir le grand Baron «pâlir et rougir successivement ${ }^{4} »$ en jouant Cinna, et Mlle Dumesnil traverser la scène en courant dans Mérope, sous l'effet de la passion violemment ressentie 5 .

Les fragments spectaculaires sont l'objet d'un traitement ambivalent, révélateur d'un désir de les rendre exemplaires sans réduire leur caractère inouii. D'une part, rapportée sous forme d'anecdote délicieusement frappante, le «je ne sais quoi» se dérobe à l'explication et voit son mystère s'épaissir d'un texte à l'autre. Dans la tragédie, explique Sainte Albine, «on s'abandonne aux mouvements que le Comédien excite. On n'examine point par quelle route il parvient à les faire naître ${ }^{6} \gg$. D'autre part, plutôt que de déduire des préceptes immuables à partir de ces échap-

\footnotetext{
1. Sur ces questions, voir Sabine Chaouche, Écrits sur l'art théâtral. 1753-1801, t. I, Paris, Champion, 2005, «Introduction», p. 15-42; et Baldine Saint-Girons, Le Sublime de l'Antiquité à nos jours, Paris, Desjonquères, 2005, p. 93-110.

2. Rémond de Sainte Albine, Le Comédien, Paris, Desaint et Saillant, 1747, p. 112.

3. Denis Diderot, Entretiens sur le Fils naturel [1757], dans CEuvres, tome IV : Esthétique-Théâtre, Paris, Robert Laffont, coll. «Bouquins», p. 138.

4. Claude-Joseph Dorat, Essai sur la déclamation tragique, Paris, 1761, p. 21.

5. Voir entre autres mentions de l'anecdote, Vincent Arnault, Les Souvenirs et les regrets du vieil amateur dramatique, Paris, C. Froment, 1829, p. 58-60.

6. Rémond de Sainte Albine, Le Comédien, op. cit., p. 30.
} 
pées imprévisibles, les auteurs de traités s'attachent au contraire à remonter en amont de la représentation et à définir les conditions d'épanouissement du jeu sublime. Le principe repris dans chaque traité est simple: il ne s'agit pas de copier de l'extérieur le jeu de ces grands comédiens, mais de puiser directement dans la nature en se dépossédant de soi, en devenant le personnage et en se livrant aux sentiments éprouvés. Les défenseurs de Shakespeare ne disent pas autre chose lorsqu'ils préconisent, non pas d'imiter les œuvres du dramaturge élisabéthain, mais, comme lui, de s'inspirer directement de la nature. Le comédien ou le dramaturge ouvriraient alors la voie à un nouveau type de théorisation, fondé sur la transmission d'une méthode de création ouvrant à des productions diverses et singulières, plutôt que sur l'énoncé de codes définissant par avance le résultat à produire.

\section{Catégorie}

La mise en avant d'un ou plusieurs individus singuliers au sein d'une catégorie empêche souvent de penser cette catégorie elle-même, ou d'élaborer des lois de la nature ou de la société. Par exemple le monstre, dont la singularité, voire l'aspect spectaculaire, rendent à nos yeux légitime de le ranger dans une classe particulière, est en même temps rarement l'occasion de remettre en cause l'ordre général des phénomènes dont il procède. Le présupposé est connu: tout effet a sa cause, les anomalies ne sont rien d'autre que l'expression de causes inconnues et elles ne peuvent contredire la structure générale du monde que la raison a la capacité de découvrir. Ainsi, chez Bacon, «l'histoire des monstres» est subordonnée à «l'histoire des générations ${ }^{1} »$ : identifier des monstres revient à mesurer la déviation de certaines réalités par rapport à l'ordre réglé de la nature. Chez Diderot, bien que l'étonnement et la curiosité que le monstre suscite doivent nous inviter à penser ces mêmes lois, on retrouve une confiance identique en la rigidité des lois de la nature et partant, des catégories : «L'homme n'est qu'un effet commun, le monstre

\footnotetext{
1. Voir sur ce point Francis Bacon, Parasceve ad historiam naturalem et experimentalem, dans The Works of Francis Bacon, éd. de J. Spedding, R.L. Ellis et D.D. Heath, London, 1858-1874, vol. II, p. 47.

2. Denis Diderot, Le Rêve de d'Alembert [1769], Paris, Garnier Flammarion, 1965, p. 93.
} 
qu'un effet rare; tous les deux également naturels, également nécessaires, également dans l'ordre universel et général.»

Quand arrive un phénomène qui bouscule les frontières d'une catégorie - le monstre est-il comme l'homme le produit de la génération? Si oui, remet-il en question notre compréhension des lois biologiques ou de la nature ? -, on bouleverse rarement l'ordre établi, préférant considérer le monstre comme une aberration ou une exception qui, selon l'expression consacrée, confirme la règle: placé «en déviation de» comme l'on s'écarte du droit chemin, ou même «hors la loi» tel un brigand de l'Ouest lointain, le phénomène n'est plus en position d'instruire la raison sur ses insuffisances. Il est désormais exclusivement soumis au règne contraire de l'émotion.

Dans le dernier tiers du XVIII ${ }^{\mathrm{e}}$ siècle quelques apprentis-décrypteurs du monde social ont eux aussi désigné des personnages extraordinaires comme autant d'aberrations individuelles dans un ordre social jamais remis en cause. Entre le début des années 1770 et celles qui précèdent immédiatement la Révolution française, surgissent nombre de textes regroupant des anecdotes morales, visant à illustrer la vision pleine d'espoir du sentimentalisme nouveau. Celui-ci, confiant dans les pouvoirs d'une raison humaine appuyée sur des sentiments naturels présents en chacun, y voit les éléments fondateurs d'une possible vertu. Les anecdotes, dont les acteurs sont souvent d'origine populaire, visent à susciter l'étonnement en exhibant le décalage entre les actions des individus présentés et ce qui serait attendu de la catégorie sociale à laquelle ils se rattachent: mettre en valeur leur action individuelle tend à constituer une accusation d'autant plus grande de la classe en général. Ainsi l'histoire du dénommé Voirey intéresse-t-elle dans la mesure où ce domestique, occupé à servir son maître ruiné, «n'est plus un homme ordinaire », et ce, alors même qu'il est dit appartenir (et c'est ce rappel qui donne sens à la chose) à la classe «la plus corrompue, la plus dégradée peut-être, de la nation ${ }^{1} »$.

Deux auteurs, qui font le même récit illustrant la probité et la générosité d'un voleur domestique, le font ainsi en soulignant de manière semblable leur étonnement: condamné dans le ressort de Bar-sur-Aube à être pendu, l'individu s'évade des mains des quatre archers qui devaient

1. François-Thomas-Marie de Baculard d'Arnaud, Délassements de l'homme sensible, ou anecdotes diverses, Buisson, 1785. 
le conduire à Paris. Les archers arrivés sans leur prisonnier sont écroués comme responsables. Comme on allait faire le procès de ces derniers, «le criminel, ne pouvant étouffer les remords de sa conscience, fut assez généreux pour se déterminer à venir les délivrer aux dépens de sa vie». Cet acte est jugé «d'autant plus étonnant qu'il partait d'un homme qui devait en paraître incapable» et, en raison justement de ce caractère exceptionnel, alla jusqu'à être rapporté au Régent ${ }^{1}$. L'admiration pour des individus issus du peuple porte ici non pas à réviser un jugement généralisant sur cette classe méprisée mais à plaindre le seul individu qui y appartient, par erreur. Nous voilà donc en présence d'un individu d'exception dont la valeur inexpliquée renvoie à la pauvreté du groupe.

Rien n'interdit de retrouver un Voirey dans la presse actuelle, celle qui met en avant les performances extraordinaires de quelques «Arabes» singuliers, pour mieux stigmatiser les autres. Ainsi, selon Deltombe et Rigouste, «dans [le] contexte [actuel] où "l'Arabe qui a réussi" n'existe que dans la performance, la figure de Zidane compose l'image d'une exception - le "miracle"! - renvoyant le reste des "Arabes" à l'échec ».

Dans certains contextes, la constitution des icônes peut cependant servir la valorisation sociale du groupe entier d'où l'exception a été extraite. C'est le cas du grand acteur britannique David Garrick, fondateur dans les années 1740 d'un nouveau jeu «naturel» rompant avec la déclamation. Le «Newton du théâtre ${ }^{3}$ », fascine les philosophes français qui le côtoient dans les salons parisiens en 1751, 1763 et 1765. Objet d'anecdotes sensationnelles colportées dans toute l'Europe, l'engouement qu'il suscite contribue très largement à faire du jeu du comédien un art à part entière et à lui accorder une place de choix aux côtés de la poésie et de la peinture. Somme toute, profitant notamment de la «starisation» de Garrick, les comédiens français, excommuniés d'office dès lors qu'ils choisissaient d'embrasser la carrière dramatique, sortent peu à peu de l'état «infâme» où ils étaient cantonnés, et se voient accorder le statut de citoyen après la Révolution française.

\footnotetext{
1. Anonyme, L'École du Bonheur, Paris, Rue et Hôtel de Serpente, 1782, p. 198-199; et LaurentPierre Bérenger, Le Peuple instruit par ses propres vertus; ou Cours complet d'instructions et d'anecdotes recueillies dans nos meilleurs Auteurs, et rassemblées pour consacrer les belles actions du peuple, et l'encourager à en renouveler les exemples, Paris, Nyon L'âné, 1787, p. 183-184.

2. Thomas Deltombe et Mathieu Rigouste, «L'ennemi intérieur: la construction médiatique de la figure de 1"“Arabe" ", dans Pascal Blanchard, Nicolas Bancel et Sandrine Lemaire (dir.), La Fracture coloniale. La société française au prisme de l'héritage colonial, Paris, La Découverte, 2005, p. 196. 3. Thomas Davies, Memoirs of the Life of David Garrick, London, 1781 [1780].
} 


\section{HORS NORME?}

Comment penser l'écart sans penser la norme? Le plus grand des génies, celui dont l'écart à la norme atteint une dimension aussi grande que possible échappe-t-il à la normalisation? Cet être dont le talent, relativement à la majorité des mortels, constitue presque une pathologie, peut-il être pensé en dehors de toute référence commune? Quelle est sa vraie valeur, et comment l'évaluer, s'il n'est point l'initiateur, le référent originel, d'une discipline, d'une académie, d'un style ou d'un système?

Lorsque Kant, au § 46 de la Critique de la faculté de juger, définit le génie comme celui dont la nature (innée) donne ses propres règles à l'art, il le place d'emblée dans une autre sphère que ses prédécesseurs. Le génie ne doit rien à l'apprentissage. Mais parce qu'il est originel, il se doit aussi d'être exemplaire et de faire école car tous les êtres de raison ne sont pas dotés d'une faculté d'imagination qui puisse les soustraire entièrement aux règles de l'art et de la pensée. Le génie, au commencement d'une série, est l'être autour duquel se structure un nouvel ordre spécifique, un style artistique, une catégorie esthétique, etc. Transcendant les normes du passé vis-à-vis desquelles il exprime son indépendance, il est créateur des normes de l'avenir.

Selon cette acception, le concept du pathologique chez Canguilhem semble partager avec le génie chez Kant une similitude. L'une des thèses de Canguilhem est que l'on ne peut objectiver la norme sur des bases statistiques. Le pathologique n'est pas une déviation par rapport à ce que l'on considère comme normal et la maladie n'est pas l'écart quantitatif par rapport aux moyennes physiologiques de ce qui est sain. La maladie est elle-même l'instauration de nouvelles normes qui la rendent indépendante de son rapport à l'ancienne norme, qui la placent «endehors de cette ancienne norme»: le pathologique se tient dans l'écart qui s'ouvre entre la norme de vie la plus répandue dans un même corps social et l'état de mort; il n'est pas l'expression négative d'un désordre, mais ce qui - par le biais d'une extraction à l'univers régi par la norme devient la forme positive d'une nouvelle normativité. Créatrices de nouvelles valeurs, les maladies sont-elles pour autant géniales? En un sens oui. Mais Canguilhem n'a jamais rompu entièrement le lien entre le normal et le pathologique, comme Kant a pu le faire entre le génie et l'homme 
au talent simple, élevant l'exception au-delà de toute comparaison. La normativité d'un individu sain n'est pas de même valeur que celle d'un individu malade. La maladie est une réduction de la marge de tolérance du vivant aux agressions de son milieu, une atteinte à la capacité d'adaptation qui est optimale à l'état de santé. La commensurabilité de la santé (normal) par rapport à la maladie (pathologique), aussi hétérogènes soient-elles, subsiste donc et se fonde sur les capacités adaptatives du vivant. Qu'il s'agisse de Kant ou Canguilhem, les catégories du génie et du pathologique ouvrent toujours, chacune à leur manière, vers de nouvelles normes. Il y une dimension «normative» des exceptions et de l'extraordinaire.

\section{RÉvOLUTION}

Le 3 décembre 1792, alors que la République a deux mois à peine et que s'engage le débat sur le procès du roi, Robespierre lance à la tribune de la Convention: "Vous confondez une nation qui punit un fonctionnaire public, en conservant la forme du gouvernement, et celle qui détruit le gouvernement lui-même. Nous rapportons à des idées qui nous sont familières un cas extraordinaire, qui dépend de principes que nous n'avons jamais appliqués ${ }^{1}$.» La Révolution met en place un inconnu pratique, qui est aussi celui des principes de nos actions: sur quelles bases reconstruire un ordre politique, juridique, épistémologique, etc., quand on a rejeté l'ensemble des normes jusque-là en vigueur? La gestion d'un ordre inconnu nécessite en théorie de réelles innovations qui en sont la véritable mesure. On ne saurait évaluer une révolution sur la base de la disparition d'un système (politique ou rationnel), sans pouvoir le confronter à celui qui le remplace.

Ainsi, quand Robespierre scande la Révolution, c'est l'application des principes, avant même leur nouveauté (ou parfois malgré elle), qui importe. Une révolution qui, souvent dans l'urgence, a besoin de trouver les bases de sa permanence peut les trouver soit dans une exception pre-

1. «Discours sur le jugement de Louis XVI» (1 $1^{\text {re }}$ intervention), prononcé à la tribune de la Convention le 3 décembre 1792, dans Charles Vellay, Discours et rapports de Maximilien Robespierre, Charpertier et Fasquelle, 1908, p. 213. 
mière (et qu'elle déplore) à l'ordre qu'elle vise à reconstruire, soit dans un ordre systématique alternatif. Dans le premier cas, il s'agit d'ériger en norme l'exception pratique, de même que la contrainte pensée en 1793 comme nécessaire pour rétablir le droit et la justice menacés par la contre-révolution. Cette exception pratique s'affranchit et du passé et de l'avenir - n'étant pensée que comme temporaire. La Révolution fait ainsi voisiner la Terreur, un moment de répression, et l'invention de la liberté, puisqu'elle est «en même temps, et contradictoirement, fondation des libertés antirépressives d'Occident ${ }^{1} »$. Dans le second cas, la gestion de l'extraordinaire relève soit d'une procédure d'importation de concepts anciens ou d'invention de nouveaux concepts, d'outils, de modèles pratiques (c'est le cas par exemple de l'introduction en 1789 du droit naturel en politique), soit d'une manière d'ériger en norme ce qui, dans le passé, était une exception pratique (l'universalisation des droits individuels jusqu'alors réservés à une catégorie sociale minoritaire). Dans ce second cas, la révolution se rattache profondément au passé.

Cette procédure d'instauration d'un ordre nouveau en s'appuyant sur ce qui constitue pour lui une exception est aussi le facteur opératoire d'autres révolutions: scientifiques, par exemple. Un premier exemple tiré des sciences biologiques illustre la généralisation d'un fait minoritaire: c'est celui de la théorie cellulaire qui naît dans les années 1830. Jusqu'à cette époque, les observations microscopiques (mauvaises, à cause des limitations techniques) laissaient croire à l'hétérogénéité radicale des structures tissulaires dans l'organisme. Loin d'être considérée comme «l'unité fondamentale de la vie», la cellule était perçue comme un composant parmi d'autres du vivant. En 1838, dans ses Beiträge zur Phytogenesis [Contributions à la phytogénèse], puis en 1841 dans les Grundzüge der wissenschaftlichen Botanik [Principes fondamentaux de la botanique scientifique], le botaniste allemand Jakob Mathias Schleiden généralise par une procédure inductive l'idée que la cellule est une unité fonctionnelle capable de se diviser et que toute cellule provient d'une cellule: c'est une idée que son contemporain Theodor Schwann appliquera au règne animal. Avec cette théorie, les problématiques d'investigation, ainsi que les procédures de recherche et d'organisation du savoir, se trouvent bouleversées en vue d'une analyse centrée sur un nouvel objet. Le second exemple concerne la manière dont les transfor-

1. Jean-Pierre Faye, Dictionnaire politique portatif en cinq mots, Gallimard, 1982, p. 62. 
mations du langage ont réorienté radicalement la recherche dans le domaine des mécanismes de reproduction. La succession de diverses métaphores et analogies a notamment permis le passage d'une analyse centrée sur le rôle des spermatozoïdes à celle de mécanismes coopératifs entre l'ovule et le spermatozoïde. La thèse est présentée par Evelyn Fox Keller:

Il y a vingt ans [le processus de fécondation] pouvait être décrit [...] dans des termes évoquant le mythe de la Belle au bois dormant (pénétration, conquête et réveil de l'œuf par le spermatozoïde, par exemple), précisément parce que cette imagerie correspondait aux stéréotypes sexuels dominant. De nos jours, $[\ldots]$ on a plutôt tendance à parler de la fécondation dans le langage de l'égalité des chances - définie, par exemple, comme le «processus de rencontre et de fusion de l'ovule et du spermatozoïde ». [...] Dans ce cas de la fécondation, chacune des deux métaphores successives à sa propre productivité scientifique. La première a entraîné une investigation intensive des mécanismes moléculaires de l'activité spermatique [...] tandis que la seconde a stimulé les recherches qui ont permis d'élucider les mécanismes à travers lesquels l'œuf pouvait être considéré comme actif $^{1}$.

La transformation métaphorique dont parle E.F. Keller n'est pas simplement due aux évolutions d'un ordre politique (passage de la domination masculine à l'ère des revendications féministes), mais entend aussi compléter les insuffisances épistémiques d'une explication. Le modèle égalitaire de la coopération des gamètes dans la fécondation, longtemps ignoré par les scientifiques car parfaitement extérieur à l'ancien paradigme idéologique (scientifique et moral), est venu se substituer à la norme épistémologique dominante. Dans cet exemple, comme dans le précédent, on reconstruit un ordre, non à partir de rien, mais à partir de ce qui constituait une donnée extraordinaire dans le contexte du système détruit. Dans le premier cas, l'élément rare d'une structure en devient l'élément fondamental. Dans le second cas, la reconfiguration s'opère à partir de l'importation, depuis un domaine extérieur, d'un concept, d'une idée, à la signification déterminante pour l'interprétation du nouveau système.

Le cas de la généralisation de l'exception, qui intervient comme modalité du processus révolutionnaire pour instaurer un ordre nouveau, met en

1. Le Rôle des métaphores dans les progrès de la biologie, Paris, Institut Synthélabo, 1995, p. 12. 
évidence la dualité du phénomène révolutionnaire, jamais totalement affranchi du passé. La révolution en acte recompose un ordre, notamment à partir des éléments dont elle dispose. Elle doit jouer avec la continuité temporelle, le temps réel, métaphysique, qui n'est pas celui de la reconstitution par ses historiens. Aussi violente soit-elle, la révolution ne réduit pas à néant l'environnement des hommes qui la font. La révolution française n'a pas inventé l'idée de liberté mais - pour paraphraser Robespierre - a généralisé l'application de son principe.

Est-ce à dire que l'on doive abandonner la rupture au profit de la continuité? Adoptant le point de vue d'une histoire des pratiques de production des savoirs, Steven Shapin va jusqu'à nier qu'une révolution

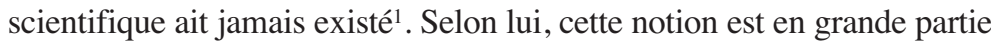
une création des historiens du milieu du $\mathrm{XX}^{\mathrm{e}}$ siècle : la révolution mise en avant par les historiens ne surgit jamais que comme reprise et continuation du passé. Thomas Kuhn défend une position rigoureusement inverse : à travers la définition du «précurseur», il analyse comment les manuels scientifiques gomment les discontinuités pour faire apparaître une linéarité factice de la pensée à travers l'appropriation successives des précurseurs par leurs contemporains. Mais Kuhn comme Shapin exhibent, à l'appui de leur thèse, des stratégies du discours: les historiens gomment/construisent les discontinuités. Répondre à un problème qui relève de "l'ordre des choses» en s'appuyant sur un diagnostic qui concerne «l'ordre du discours»: c'est l'essence même des querelles d'interprétation qu'on ne saurait trancher par l'exhibition de faits. Légitimer la révolution comme schème historique en exhibant une évidence factuelle est sans doute voué à l'échec, quand bien même il serait possible de repérer dans les archives, dans les textes même, des ruptures que Michel Foucault avait le talent de mettre en scène ${ }^{2}$. Peut-être n'y at-il alors de révolutionnaire que ce que la pensée refuse de penser sous la catégorie de l'ordinaire, dès lors qu'elle se trouve interpellée par un semblant de rupture ou de crise dicté par l'émotion?

1. Steven Shapin, La Révolution scientifique, Paris, Flammarion, 1998.

2. Voir par exemple, Michel Foucault, Naissance de la clinique, «préface», Paris, PUF, coll. «Quadrige », p. v-viii. 


\section{ÉVÉNEMENT}

Comment qualifier un événement d'historique? Ériger le sensationnalisme en critère de compréhension du monde? Même si l'événement est un avènement en ce qu'il s'ouvre et résiste à l'expérience, et qu'il échappe à une appropriation totale (il est d'abord l'incompréhensible), la tendance à l'ériger en origine d'une nouvelle ère ne masque-t-elle pas un échec à penser sa nouveauté réelle? Déterminer à l'emporte-pièce un avant et un après, dont un événement constituerait le point de bascule, n'est-ce pas se fier trop commodément à un appareil conceptuel traditionnel et inadapté à l'émergence de l'inédit ? C'est ce qu'affirme Derrida dans Le «concept» du 11 septembre 1 . Les concepts de «guerre » et de «terrorisme» dont on a usé et mésusé pour tenter de comprendre l'événement du 11 septembre, tombent en obsolescence devant cette tragédie. Rejeter le sensationnalisme, qui sert tant le terrorisme que l'arsenal des médias, revient à accepter le tremblement des oppositions conceptuelles du national à l'international, du civil au militaire - ce qui suppose un effort intellectuel de longue haleine pour penser à nouveaux frais ce qui est arrivé. Il nous apparaît ainsi que la rupture du 11 septembre 2001 vient peut-être de ce que cet événement a modifié la configuration qui conditionnait certains de nos schèmes mentaux au service de l'action. Il semblerait que la conjugaison des temps sous-jacente à la projection mentale d'une gamme de possibles permettant l'anticipation et guidant une action dès lors informée (un futur pensé en fonction d'un présent riche d'un passé synthétisé en expérience) se soit grippée. Désormais, le futur terrifiant qui plane de façon obsessionnelle à travers la menace terroriste conduit à tout appréhender à rebours, vampirisant un présent exsangue de ce potentiel infini, réduit à un segment menant irrémédiablement à la catastrophe. Le point de départ de ce raisonnement téléologique ne se situe plus dans le présent mais dans le futur, laissant l'espoir de contrer la réalisation de ce qui n'a pas encore eu lieu. Il ne faut donc pas raisonner en termes d'avant et d'après au sens d'accident et de rupture, de collisions entre des séries extérieures l'une à l'autre.

1. Jacques Derrida, Le «concept» du 11 septembre. Dialogues à New York avec Giovanna Borradori, Paris, Galilée, 2004. 
De telles tensions sont patentes lorsque l'extraordinaire à penser est celui d'une crise. D'un côté, on chercherait un lien entre la crise et le contexte qui l'encadre; de l'autre, on voudrait plutôt penser le phénomène extraordinaire sur le mode de l'accident. Cependant, la crise n'est pas un accident, elle ne vient pas briser une évolution qui suivait indépendamment son cours. Pas plus qu'on ne trouve aux prises deux séries dont la collision au hasard bouleverserait la donne. À rebours d'une attention démesurée au spectaculaire de la rupture, il faut une prise en compte raisonnée de sa contingence et de son imprévisibilité: la crise n'est pas imprévisible, bien que contingente. Tout est question de temps: plus qu'une succession de tableaux statiques où régnerait un ordre spécifique, la crise procède d'une dynamique en perpétuel réajustement, qui correspond le mieux au mécanisme du changement. Il faut donc admettre que l'objet «crise» autorise une certaine cohérence. Le voici alors investi d'une dimension heuristique puissante: la crise révèle, par ses dysfonctionnements, un système. Ce qui n'annule pas pour autant la part irréductible de nouveauté qui érige la crise en événement souverain et dont on ne rend pas compte sans bouleverser les catégories de l'entendement historique que sont l'«époque», le «contexte», la «société» ou le «milieu».

À moins que l'on ne gomme la singularité irréductible de l'événement, par le biais d'un travail sur la répétition et le rite. Semblable exclusion de l'extraordinaire événementiel a puissamment contribué à la construction de l'ethnologie des deux derniers siècles. Elle ne touchait au $\mathrm{XIX}^{\mathrm{e}}$ siècle que le recueil de données, puis s'est étendue à l'habitus de l'ethnologue lui-même, lorsque celui-ci s'est fondu avec l'ethnographe au $\mathrm{XX}^{\mathrm{e}}$ siècle. On constate un tournant significatif dans les théories de l'anthropologie à ce moment-là: en passant des évolutionnismes aux fonctionnalismes puis aux structuralismes, on glisse de modèles diachroniques à des modèles synchroniques, c'est-à-dire à des modèles qui mettent en périphérie de leurs démarches la question du changement. Autant le changement est omniprésent pour l'historien - il n'a pas d'ailleurs besoin de recourir à cette sémantique -, autant l'ethnologue le trouve dérangeant - d'où le recours à une sémantique du changement, comme s'il fallait qu'il s'en fasse raison. Alban Bensa et Éric Fassin ne disent pas autre chose lorsqu'ils constatent que la description ethnographique privilégie généralement le quotidien et la répétition rituelle plutôt que les fêlures ou les ruptures et que, dans ce cadre conceptuel, 
l'événement pose problème à l'anthropologie et plus généralement aux sciences sociales ${ }^{1}$.

Il existe donc une défiance théorique pour l'extraordinaire, sans doute en raison d'un cadre conceptuel structuré par une attention à la régularité, à l'ordinaire et au continu. Par ce déni psychologique d'extraordinaire, l'ethnologie s'est interdit pendant longtemps tous ces objets «extraordinaires» qu'étaient, par exemple, les crises, les événements imprévus, les ruptures temporelles, les discontinuités sociales, laissant cela aux historiens spécialistes du changement, de la diachronie et de l'instable. Et lorsqu'un domaine, comme le religieux, présente une propension à l'extraordinaire, tout est fait pour reconstruire du régulier, du répété, notamment grâce à des outils théoriques comme le rituel qui sert trop souvent à l'ethnologue à repriser ce qui lui apparaît comme indécemment discontinu. Nous pourrions prendre ici le cas du carnaval: voilà une évidente rupture avec le quotidien, qui est dépeint comme un rite d'inversion des organisations et des rapports sociaux, c'est-à-dire comme une régularité, un continu, un ordinaire. Sa dimension extraordinaire semble être balayée et mise de côté alors même qu'elle est centrale pour les participants du rite. Et c'est sans doute là où le bât blesse. Si l'anthropologie, par l'ethnographie, s'est construite contre l'extraordinaire, si les anthropologues ne pensent pas par l'extraordinaire et si ce n'est pas là leur cadre théorique, ils semblent qu'il aient aussi oublié de penser ce que voulait dire «extraordinaire» pour les acteurs eux-mêmes. Certes, le carnaval est un rite répété chaque année avec souvent les mêmes rituels, mais il est vécu aussi comme événement extraordinaire, qui rompt avec le quotidien et l'ordinaire.

\section{MiraCle}

Si l'on entend par événement un phénomène inhabituel, inattendu et significatif, il a tout du miracle. Du moins dans la vision qu'en ont proposé certaines théologies de l'Occident médiéval, l'augustinienne au premier chef. Le miracle apparaît communément comme une exception, un fait ou un acte sorti de l'ordinaire en échappant aux lois naturelles, s'y

1. Alban Bensa et Éric Fassin, «Qu'est-ce qu’un événement?», Terrains, n³ 38, 2002, p. 5-20. 
soustrayant, les contredisant même. Pas d'explication rationnelle au miracle. C'est un prodige devant lequel il faut s'émerveiller: la guérison des aveugles, l'ouverture de la mer Rouge, la résurrection des morts sont autant de phénomènes impossibles au quotidien ou qui ne sauraient survenir de manière régulière.

Mais historiquement, cette conception du miracle comme rupture phénoménale du cours ordinaire des choses et comme violation des lois naturelles survient assez tardivement. Jusqu'au XI ${ }^{\mathrm{e}}$ siècle, c'est la conception d'Augustin qui prévaut: si le miracle peut être dit extraordinaire, ce n'est pas parce qu'il détourne les lois de la nature, mais en raison de la réalité divine ou de la vérité spirituelle qu'il signifie; il est théophanique:

Ces phénomènes qui appartiennent aussi au monde corporel, mais qui ont la mission de transmettre à nos sens quelque message divin [...], c'est ce qu'on appelle à proprement parler des miracles ou des signes ${ }^{1}$.

Le fait que le miracle ne soit pas exactement conforme aux lois de la nature le rend reconnaissable, mais ne le caractérise qu'en second lieu. Dieu n'intervient pas comme une cause exceptionnelle qui permette l'avènement de l'inouï, de l'insolite, mais il agit lui-même comme une cause naturelle. Si le miracle a Dieu pour cause, il n'en est pas moins conforme à la nature - sinon, il ne pourrait pas y apparaître ${ }^{2}$ et Dieu ne peut contredire les lois qu'il a lui-même instituées; sa volonté ne peut être contraire à elle-même.

Voici donc un phénomène qui se présente à la raison suivant une causalité double et simultanée. C'est qu'Augustin conçoit la causalité naturelle comme le résultat de la délégation de la causalité divine: les «causes secondes» (ou «raisons séminales») récupèrent la force causale de la «cause première » et assurent la pérennité de l'ordre, par la nécessité de leurs effets; la liberté de la causalité divine est ainsi relayée par la nécessité de la causalité naturelle, sans que cela rende impossible l'intrusion exceptionnelle de l'ordre libre dans l'ordre nécessaire. Bien plus, les raisons séminales des créatures prévoient la possibilité d'une causalité divine ${ }^{3}$. Dieu, par le moyen ordinaire des causes secondes, cause

1. Augustin, De trinitate, III, X, 19, Bibliothèque Augustinienne, Paris, IEA, 1997, t. XV, p. 310-311.

2. Idem, IX, 16, op. cit., p. 304.

3. Augustin, De genesi ad litteram, IX, XVII, 32, Bibliothèque Augustinienne, Paris, Desclée de Brouwer, 1972, t. XLIX. 
donc librement, volontairement, pour une raison précise, et suffisante pour nous si nous parvenons à la saisir par l'herméneutique des signes. Ainsi y a-t-il continuité et compatibilité entre l'ordre et l'extraordinaire: le second dépend du premier, parce qu'il tient de lui sa puissance propre; le premier peut s'intégrer dans le second sans le déranger.

Augustin met au second plan le caractère inhabituel, insolite, inouï du fait miraculeux ; il place au premier plan son caractère admirable et significatif. Il considère ainsi que la création est le plus grand et le plus admirable des miracles... et pourtant, rien de plus ordinaire que la créature! De même François d'Assise loue la nature avec la conscience du caractère unique et parfait, impossible à reproduire, de cette œuvre qui nous est familière. Le miracle est connu, accessible aux hommes auxquels son sens est destiné; en même temps, le message sacré dont il est porteur est toujours nouveau, admirable. L'acte miraculeux n'est pas une transgression mais l'intervention d'un sens : à un événement qui n'a pour signification que lui-même, Dieu ajoute une signification eschatologique ou messianique. Aussi, quand on parle de la cause «surnaturelle» du miracle, on entend l'intention divine de faire porter son message à l'événement. La familiarité côtoie l'émerveillement jusqu'au paradoxe, dans cette esthétique miraculeuse; les miracles sont quotidiens à qui sait voir les choses avec l'œil de la spiritualité. Comme le rite, le miracle assure dans l'ordinaire le surgissement du sens, du sacré : l'importance se dévoile, apparaît brutalement dans une réalité peinte en relief, doublée de l'intention qui préside à sa présence.

\section{EXCENTRICITÉ PRIMITIVE}

Soit Shakespeare. Les commentaires consacrés à son œuvre au XVIII ${ }^{\mathrm{e}}$ siècle s'accordent à souligner qu'il ne respecte pas les règles édictées par Aristote, et fondatrices de la poétique classique informant la production tragique française. Pour la plupart, les théoriciens attribuent ce nonrespect des règles, non pas à une volonté délibérée de les enfreindre, mais à la méconnaissance qu'en avait Shakespeare. Manière de prendre la défense du dramaturge anglais en mettant paradoxalement en avant son ignorance: vivant dans un siècle barbare et étant, par opposition à son contemporain Ben Jonson, un homme de théâtre peu lettré qui écrivait avant tout pour la scène et non pour être lu, Shakespeare «n'a pas connu 
les unités ». Par conséquent, «il y aurait injustice à le juger par les règles de l'art, puisqu'il ne les a jamais connues ${ }^{1} \gg$.

En somme, pour comprendre Shakespeare, il faudrait changer d'angle de vue, déplacement dont permet de rendre compte cette métaphore juridique de Pope - l'un des premiers, en 1725, à expliquer qu'on ne peut pas évaluer la qualité des œuvres de Shakespeare avec les règles d'Aristote: cela reviendrait à «juger un homme avec les Lois d'un Pays, alors qu'il a agi sous celles d'un autre ${ }^{2} »$.

Shakespeare est perçu comme extraordinaire au sens fort du terme: il ne s'oppose pas à l'ordre, puisqu'il ne le connaît pas, mais est en dehors de l'ordre, étranger à lui; il est, selon les termes de Voltaire, un «sauvage ivre $^{3} »$, un barbare qui n'est pas au fait de l'ordre grec. Pour les hommes de la première moitié du XVIII ${ }^{e}$ siècle, il donne à voir la nature à l'état brut, dans sa variété chaotique, désordonnée, qui intègre le transitoire, l'accidentel et le particulier (les passions monstrueuses, les personnages surnaturels), sans faire apparaître un ordre réglant la signification de manière univoque. Ce faisant, il affirme sa singularité et n'offre pas prise à l'intégration, au processus de civilisation du Huron. Le dramaturge élisabéthain est ainsi un génie au sens où l'entend le XVIII ${ }^{\mathrm{e}}$ siècle ${ }^{4}$ : par son caractère inné, fondé sur des dispositions naturelles, il est irréductiblement original, au sens de primitif, renvoyant à l'origine, et d'unique, d'excentrique.

En se situant en dehors des cadres, Shakespeare fait apparaître le caractère relatif des normes esthétiques du classicisme. Dès 1738, l'auteur et acteur italien émigré en France Luigi Riccoboni examine timidement la possibilité d'utiliser d'autres critères de jugement que les règles de la poétique classique ${ }^{5}$, et en conclut que Shakespeare pourrait alors rivaliser avec les autres dramaturges, «anciens et modernes». Le traducteur Pierre Antoine de La Place radicalise le propos en 1745 lorsqu'il se réclame de la «différence des temps, des mœurs, et des usages» pour

\footnotetext{
1. Abbé Prévost, Le Pour et le Contre, t. XIV, 1738.

2. «To judge therefore of Shakespeare by Aristotle's rules, is like trying a man by the Laws of one Country, who acted under those of another.», Alexander Pope, "Preface to Shakespeare", dans The Works of Shakespeare, éd. A. Pope, Londres, 1725, t. I.

3. Voltaire, «Dissertation sur la tragédie», préface à Sémiramis, 1748.

4. Voltaire rappelle en 1764 que «Shakespeare n'avait point eu d'éducation, qu'il devait tout à son seul génie». (Voltaire, Commentaires sur Corneille, «Jules César», note 39 de l'acte I, 1764).

5. Luigi Riccoboni, Réflexions historiques et critiques sur les différents théâtres de l'Europe, Paris, Guérin, 1738.
} 
stigmatiser ceux qui croient «devoir regarder avec mépris tout ce qui n'est pas frappé au coin de la politesse, et du goût épuré de notre siècle ${ }^{1}{ }^{1}$. Suit l'idée, novatrice pour l'époque, que c'est un avantage pour Shakespeare d'avoir ignoré les règles: son pouvoir de caractérisation des personnages et son inventivité en sont renforcées. Le «goût français», norme de jugement érigée à partir des préceptes du classicisme, se voit donc disqualifié dans sa prétention à juger du monde de manière universelle. L'extraordinaire shakespearien apparaît peu à peu comme un ordinaire autre, un ordinaire nouveau à côté de l'ordinaire connu jusqu'alors. Somme toute, les défenseurs de Shakespeare n'ont pas pour dessein de substituer le premier au second, mais, en usent comme d'une sorte de levier destiné à introduire du jeu au sein du système ordinaire.

On peut réévaluer dans cette perspective le spectaculaire revirement de Voltaire qui, après avoir, dès les années 1730, largement contribué à la diffusion du dramaturge élisabéthain en vue de régénérer la tragédie française, se range parmi ses plus violents détracteurs à partir de la publication, en 1761, de la traduction de l'anglais d'un Parallèle de Corneille et de Shakespeare. Des années 1730 aux années 1760, Shakespeare a en effet perdu de son exotisme aux yeux des Français, et est si bien intégré au sein des débats théâtraux que certains théoriciens n'hésitent pas à le comparer aux plus grands dramaturges classiques, parfois en défaveur de ceux-ci. Et Voltaire de tempêter contre la banalisation de celui qui, à ses yeux, ne devait rester qu'un auteur lointain et commode dans lequel puiser avec parcimonie, selon un processus comparable à la sélection opérée par les classiques au sein de la nature brute.

En mars 1741, quand le comédien anglais David Garrick joue pour la première fois Richard III de Shakespeare, il provoque un étonnement unanime. Un compte rendu rapporte que l'accueil fut «le plus extraordinaire et le plus grand ${ }^{2} »$ qui soit. Le choc créé par cette représentation est d'autant plus intense que, ce faisant, Garrick contrevient à la règle tacite qui veut que l'on ne puisse incarner un grand rôle qu'après avoir fait ses preuves dans des rôles secondaires, les premiers rôles restant la propriété des acteurs établis. En outre, Garrick n'imite pas les générations successives d'acteurs qui se sont transmis l'interprétation des rôles shakespeariens en s'éloignant progressivement de la source.

1. Pierre Antoine de La Place, Le Théâtre Anglois, «Discours sur le théâtre», t. I, 1745, p. 7.

2. Daily Post, 20 octobre 1741. 
Faisant fi des codes établis avant lui, il propose son interprétation singulière du texte et se targue d'avoir retrouvé l'esprit de Shakespeare qui, un siècle et demi plus tôt, écrivait ses tragédies sans suivre les règles d'Aristote. Shakespeare étant considéré par les hommes du XVII$\mathrm{I}^{\mathrm{e}}$ siècle comme le porte-parole de la nature, Garrick continuerait, selon ses admirateurs, à lui donner voix en représentant ses rôles conformément à l'intention de leur auteur. Privilégiant une gestuelle muette bienséante et les nuances expressives de la physionomie, Garrick poursuit en effet la tradition des pantomimes antiques et du jeu muet (dumb show) élisabéthain, dans lesquels les philosophes voient s'incarner les «signes naturels» faisant fusionner le signifiant gestuel et son référent sensible. C'est dans cette perspective stratégiquement laudative que le biographe du comédien explique le passage chez les spectateurs de l'étonnement à la reconnaissance de la vérité de la représentation: une fois le premier effet de surprise et l'hésitation initiale passés, les spectateurs auraient été conquis par le jeu de Garrick, marqué par les «manifestations authentiques de la nature ${ }^{1} \gg$.

\section{CRITIQUe de L'ÉTONNEMENT}

L'étonnement naît de la conscience d'un écart entre une chose et un ensemble de savoirs constitués permettant de s'orienter dans le monde, de l'idée que cette chose «sort de l'ordinaire», parce qu'elle se produit pour la première fois, ou que les caractéristiques qu'elle présente ne se laissent pas ramener à du déjà connu. Mais si l'on s'étonne du peu connu, on s'étonne de peu, et la conscience scientifique peut s'effrayer de ce qui n'est, finalement, qu'une appréhension empirique subjective. En ethnologie, qualifier d' "extraordinaire» le quotidien de peuples étrangers, c'est témoigner d'abord d'un sentiment destiné à disparaître, celui de l'étonnement ressenti par un observateur ignorant du fonctionnement réel de cette société. Ainsi, dans L'exotique est quotidien, Georges Condominas souligne que si le sentiment exotique est parfois nécessaire à l'émergence de l'expérience ethnologique, il est cependant superficiel, voué à être rapidement éliminé par le poids et la richesse de la vie quoti-

1. Thomas Davies, Dramatic Miscellanies, t. I, p. 39-41. 
dienne ${ }^{1}$. Cependant, le fait que l'anthropologie s'intéresse au quotidien, au banal, aux «impondérables de la vie authentique», pour reprendre l'expression de Malinowski ${ }^{2}$, implique-t-il qu'elle exclut l'extraordinaire de ses investigations? Victor Segalen ${ }^{3}$ et son plaidoyer pour un exotisme pensé comme une "esthétique du divers», un extraordinaire qui constitue une dimension essentielle dans l'expérience anthropologique ${ }^{4}$, reste-t-il finalement marginal ? La progressive rationalisation de la littérature de voyage, au cours de l'époque moderne, montre que la démarche ethnographique s'est construite au détriment de cet extraordinaire: les ethnologues ont cherché à rationaliser ce qui pouvait apparaître comme extraordinaire au sens commun européen.

Dès la fin du XVI ${ }^{\mathrm{e}}$ siècle, une série de traités de conseils aux voyageurs apparaît ${ }^{5}$. Au cours des deux siècles suivants, ces traités se transforment progressivement, d'outils orientés vers la pédagogie personnelle, en des guides généraux et des questionnaires prescriptifs destinés à mener une description scientifique: "On passe ainsi de la signalisation d'un itinéraire recommandé à une enquête de caractère économique, géographique ou naturaliste où s'épuise, autant que possible, la spontanéité de la perception ${ }^{6}$.» Cette lente transformation répond à des exigences sociales. Les voyageurs écrivent pour être lus soit par leurs commanditaires (monarque, prélat, négociants), soit par un public de lecteurs privilégiés ${ }^{7}$. Ces textes ne sont donc pas des écrits intimes, à vocation privée, mais bien des écrits publics. Ils s'inscrivent dans un marché et répondent à des exigences sociales. Les relations qu'entretiennent voyageurs et lecteurs ne sont pas exemptes de tensions. Les lecteurs sont sceptiques vis-à-vis de ces chroniqueurs de l'ailleurs. Cette suspicion, conduit à une incrédulité face à ce qui est nouveau. Elle rend du même coup nécessaire une description la plus complète possible de ce qui est rencontré lors du voyage.

\footnotetext{
1. Georges Condominas, L'exotique est quotidien. La vie quotidienne d'un village montagnard du Vietnam, Paris, Plon, coll. «Terre Humaine», 2006, p. 591.

2. Bronislaw Malinowski, Les Argonautes du Pacifique occidental, Paris, Gallimard, coll. «Tel », 1989 , p. 75.

3. Victor Segalen, Essai sur l'exotisme, Paris, Le Livre de Poche, 1978.

4. Mondher Kilani, L'Invention de l'autre, Paris, Payot, 1994, p. 12.

5. Claude Blanckaert, «Histoires du terrain entre savoirs et savoir-faire», dans Claude Blanckaert (dir.), Le Terrain des sciences humaines, Paris, L'Harmattan, 1996, p. 21.

6. Ibidem, p. 22.

7. Françoise Weil, «La relation de voyage: document anthropologique ou texte littéraire», dans Britta Rupp-Eisenreich (dir.), Histoires de l'anthropologie : XVI ${ }^{e}$-XIXe siècles, Paris, Klincksieck, 1984, p. 58.
} 


\section{Penser par extraordinaire}

Au cours du XVIII siècle, les exigences du public évoluent considérablement. La littérature de voyage ne s'adresse plus alors à des amateurs de «singularités», «mais à cette partie du public qui se trouve directement intéressée, économiquement et idéologiquement, par une meilleure connaissance du monde et de ses habitants ${ }^{1} \gg$. Se met dès lors en place un processus de rationalisation des relations de voyage ${ }^{2}$. Les lecteurs, notamment les philosophes, redoublent d'exigences vis-à-vis des voyageurs qu'ils désirent «hommes des lumières", à l'instar d'un Bougainville décrit par Diderot ${ }^{3}$. On attend du voyageur qu'il rapporte des observations véridiques, fondées et exploitables par les philosophes. Dans ce contexte, apparaissent les «manuels de recommandation» aux voyageurs. L'un des premiers, écrit par Joseph-Marie de Gérando, est élaboré à l'occasion du voyage d'exploration en Océanie du capitaine Baudin $^{4}$. Si ce texte est passé à la postérité, c'est moins en raison de ses répercussions à l'époque - il est resté longtemps ignoré - que parce qu'il posait le premier les fondements de l'observation participante, avec cette prescription célèbre: «Le premier moyen pour bien connaître les sauvages est de devenir en quelque sorte l'un d'entre eux; et c'est en apprenant leur langue qu'on deviendra leurs concitoyens ${ }^{5}$.» Que nous dit-il d'autre? Ses recommandations commencent par croquer les défauts des prédécesseurs de Baudin:

Ils ne sont pas assez appliqués à nous rapporter d'exactes et complètes remarques ; il leur est arrivé comme il arrive toujours à ceux qui observent avec trop de précipitation et de légèreté, ils ont observé assez mal [...]. Comme l'homme est toujours plus curieux des nouveautés qui frappent ses

1. Michèle Duchet, Anthropologie et histoire au siècle des Lumières, Paris, Albin Michel, 1995, p. 106

2. Françoise Weil, «La relation de voyage...», op. cit., p. 63.

3. «Bougainville est parti avec les lumières nécessaires et les qualités propres à ses vues: de la philosophie, du courage, de la véracité, un coup d'œil prompt qui saisit les choses et abrège le temps des observations; de la circonspection, de la patience, le désir de voir, de s'éclairer et de s'instruire, la science du calcul, des mécaniques, de la géométrie, de l'astronomie, et une teinture suffisante d'histoire naturelle.» Voir Denis Diderot, Supplément au Voyage de Bougainville, Paris, Le Livre de Poche, 1995, p. 27.

4. Joseph-Marie de Gérando, Considérations sur les diverses méthodes à suivre dans l'observation des peuples sauvages, reproduit dans Jean Copans et Jean Jamin (dir.), Aux origines de l'anthropologie française. Les mémoires de la société des observateurs de l'homme en l'an VIII, Paris, Jean Michel Place, 1994.

5. Ibidem, p. 82 


\section{Labyrinthe, $n^{\circ} 26$}

sens que des instructions qui s'adressent à sa raison, on a attaché bien plus de prix à rapporter de ces pays inconnus des plantes, des animaux et des substances minérales, que des expériences sur les phénomènes de la pensée ${ }^{1}$.

On voit ici la défiance pour l'exotique. Les autres recommandations s'attachent à concentrer le regard du voyageur sur la vie quotidienne d'une façon méthodique, en n'oubliant aucun de ses aspects, même si la culture matérielle est laissée dans l'ombre et si l'accent est plutôt porté sur le monde symbolique. Cette attention méthodique au quotidien passe par une suspicion à l'égard de toute impression personnelle:

C'est là ce qui arrive encore, lorsqu'au lieu de nous exposer en détail les faits dont ils ont été témoins, avec toutes leurs circonstances, ils se bornent à nous dire sommairement l'impression qu'ils en ont reçue, les jugements généraux qu'ils en ont déduits sur le caractère des nations [...]. Il est inutile de retracer ici les inaptitudes auxquelles les voyageurs ont été conduits par le défaut d'impartialité, par les préventions qui résultaient de leurs opinions particulières, par les intérêts de leur amour-propre, ou enfin par impulsion du ressentiment ${ }^{2}$.

L'objectif est ici clair: «l'équation personnelle» de l'observateur, pour reprendre une autre expression de Malinowski, doit être la plus réduite possible, pour que l'observation soit la plus précise possible.

La parenté avec les manuels d'ethnographie qui suivront durant les $\mathrm{XIX}^{\mathrm{e}}$ et $\mathrm{XX}^{\mathrm{e}}$ siècles est évidente. On y retrouve le même souci du détail quotidien et de l'effacement du chercheur. Prenons ici l'exemple du manuel de Marcel Mauss où il est explicitement conseillé de ne pas s'étonner. On retrouve sous la plume de Marcel Maget des idées similaires:

Pas plus qu'aucune autre, la recherche ethnographique n'est à l'abri des sollicitations affectives. Le besoin d'évasion est à l'origine de quelques vocations; évasion vers d'autres peuples, d'autres milieux, vers le bon vieux temps où la campagne, où la stabilité illusoire d'un âge d'or contraste avec la déroutante turbulence des temps modernes. On note également l'attirance esthétique pour l'exotique ou le rustique [...]. En l'absence de

1. Jean-Marie de Gérando, Considérations sur les diverses méthodes..., op. cit., p. 75.

2.Ibidem, p. 79-80. 


\section{Penser par extraordinaire}

mobiles plus proches d'une détermination rationnelle, les résultats de telles impulsions ne sont pas à rejeter globalement et sans examen. Le snobisme devient parfois mécénat. La réduction de conflits intérieurs ou la curiosité donnent lieu, en se disciplinant, à des travaux s'élevant au-dessus de l'improvisation. Mais tant que ces impulsions n'ont pas été canalisées et orchestrées dans un programme d'action cohérent, la prédominance de l'affectif fausse l'observation par l'emploi de critères mal définis $[\ldots]^{1}$.»

Toute l'originalité de la démarche est de rendre compréhensible l'altérité en s'intéressant au quotidien, de rendre ordinaire l'extraordinaire. Si l'étonnement, qui se traduit par un attrait pour l'exotique peut être un point de départ, il n'est donc pas un point d'arrivée.

\section{EUREKÂ}

Mû par le désir de démasquer les savoirs illégitimes et de progresser dans la connaissance de ce qui l'entoure, l'étonnement joue un rôle central dans la connaissance philosophique. Il ne se réduit pas à une réaction spontanée face à une chose nouvelle, mais il peut être construit. Comme le souligne Socrate, dans le Théétète: "C'est tout à fait l'état d'un philosophe: s'étonner. La philosophie n'a pas d'autre principe que celuilà ${ }^{2}$.» Reprise par Aristote dans la Métaphysique ${ }^{3}$, scandant l'histoire de la philosophie, cette idée que l'étonnement porte d'un bout à l'autre la philosophie est explicitée par Heidegger ${ }^{4}$. Selon ce dernier, Platon et Aristote ne réduisent pas l'étonnement à une incitation à la philosophie. Articuler étonnement et philosophie, ce n'est pas pour eux constater qu'un beau jour des hommes se sont étonnés à propos de l'étant, et que, stimulés par cet étonnement, ils ont commencé à philosopher. Dans ce cas, aussitôt la philosophie mise en marche, l'étonnement serait devenu superflu et aurait disparu. L'enjeu est bien plutôt que l'étonnement régit la philosophie en chaque pas, en ce sens qu'il permet à la fois de mettre

\footnotetext{
1. Marcel Maget, Guide d'études directe des comportements culturels, Paris, Civilisations du Sud, 1953, p. xxi-xxii.

2. Platon, Théétète, $155 \mathrm{~d}$.

3. Aristote, Métaphysique, A2, $982 \mathrm{~b} 12 \mathrm{sq}$.

4. Martin Heidegger, Qu'est-ce que la philosophie?, Paris, Gallimard, coll. « Tel », 1957, p. 43-44.
} 
en arrêt devant l'étant, et d'enchaîner à ce devant quoi cette mise en arrêt se fait. Faire de la philosophie, c'est ainsi critiquer, questionner, soit rompre avec un ordre donné, mais c'est aussi penser les choses à nouveaux frais, élaborer un ordre autre. La philosophie entretient de la sorte des liens privilégiés avec l'extraordinaire: en tant qu'elle met à distance l'ordinaire, le sens commun, et en tant qu'elle va au-delà, qu'elle forge elle-même du sens.

Ce double phénomène peut être illustré par le dispositif théorique mis en place au XVII ${ }^{\mathrm{e}}$ siècle, par Francis Bacon et René Descartes, afin d'assurer la promotion de la physique moderne, qu'ils identifient à la philosophie. Dans le De Augmentis Scientiarum, Bacon fait de l'admiration, c'est-à-dire de l'étonnement, le principe de la science ${ }^{1}$. Pour lui, éprouver de la curiosité face à une chose non ordinaire témoigne d'un désir de la connaître. Par là, il met en question une idée reçue des hommes d'Église, qui discréditent toute restauration des sciences, en raison du fait que l'aspiration à trop de savoir a été la tentation et le péché originel qui entraînèrent la chute de l'homme. Il souligne l'absence de nocivité du désir de connaître: «Il n'y a absolument aucun danger dans la quantité, ou la qualité relative de savoir qu[e l'homme] reçoit, si grande soitelle $^{2}$.» Il assure ainsi la possibilité théorique d'un espace dans lequel les sciences peuvent être et croître librement. Descartes réaffirme cette possibilité. Dans les Passions de l'âme, il soutient qu'être d'un naturel admiratif, «nous dispose à l'acquisition des sciences». Cette disposition est à entretenir, parce que cultiver sa raison et s'avancer en la connaissance de la vérité dans les sciences, autrement dit, ne pas céder aux préjugés, est la meilleure des occupations de l'homme en cette vie. En effet, comme l'annonce la quatrième maxime de la morale par provision du Discours de la méthode $e^{3}$ il n'y a pas de contentements «plus doux» ni «plus innocents» en cette vie, que ceux procurés par l'activité scientifique. Ainsi, pour Bacon, comme pour Descartes, philosopher, s'étonner, ce n'est pas s'arrêter dans la contemplation d'une réalité irrémédiablement étrangère et inaccessible. Bien plutôt, c'est à la fois reconnaître le caractère inédit de cette chose, et se nourrir de la curiosité qu'elle suscite pour

1. «L'admiration [...] est l'origine de la science», Francis Bacon, De Augmentis Scientiarum,op.cit.,

t. II, p. 102.

2. Advancement of Learning, op. cit., 1858, t. VI, p. 94.

3. Les Passions de l'âme, art. 76, édition Adam et Tannery [A.T.], Paris, Vrin, 1973, t. XI, p. 385.

Pour la quatrième maxime de la morale par provision, voir Discours de la méthode, A. T., t. VI, p. 27-28. 
l'interroger et l'analyser. L'étonnement joue donc un rôle méthodologique dans l'avancement des savoirs, en tant qu'il participe de la construction du rapport à l'objet.

Mais si l'étonnement nourrit la philosophie, les sciences ne travaillent-elles pas à le réduire, en fabriquant un monde sans surprise possible, où l'on connaît la loi des choses? Imitant l'idée qu'elles se faisaient des sciences dures, les sciences humaines ont pu aspirer à la réduction de l'étonnement. Il s'agit là encore de dénoncer une façon pour les sujets de l'histoire de subir les événements, de s'en étonner, c'est-à-dire d'être pris dans leur flux et dans les émotions. Au contraire, le scientifique, historien, sociologue, anthropologue, réduirait l'étonnement, ramènerait l'extraordinaire à un ordre, une série causale, refusant l'idée de rupture qui provoquerait l'étonnement. Il s'agit alors de rapporter ce qui étonne au commencement d'une autre série ou de le replacer dans la continuité de celle qui précède. Dans cette perspective, l'extraordinaire n'existe pas, il n'est rien d'autre que le choix inadapté d'une certaine focale: les sujets contemporains de l'événement ne peuvent qu'en subir le choc, car ils ne connaissent assurément ni la série à venir ni même vraiment la série passée; les scientifiques, eux, se doivent de tracer les justes liaisons. Ainsi, les Français de 1789 ont-ils cru «se façonner autrement que leurs pères; ils n'ont rien oublié enfin pour se rendre méconnaissables », ils se sont cru les auteurs d'un événement extraordinaire qu'ils ont nommé Révolution française; mais Tocqueville replace, lui, cet événement et ses diverses facettes dans la continuité de l'Ancien Régime passé, il est convaincu «qu'à leur insu [les révolutionnaires] avaient retenu de l'ancien régime la plupart des sentiments, des habitudes, des idées mêmes à l'aide desquelles ils avaient conduit la Révolution qui le détruisit et que, sans le vouloir, ils s'étaient servi de ses débris pour construire l'édifice de la société nouvelle ${ }^{1} \gg$. Exit, donc, l'étonnement. Exit l'extraordinaire.

Dans le geste analytique lui-même se trouverait ainsi quelque chose qui produirait une réduction de l'extraordinaire. Dans «Le problème du temps historique», Simmel écrivait:

Il y a, semble-t-il, un principe universel selon lequel, passé un certain seuil, la fragmentation d'un phénomène en éléments dont il est supposé être la

1. Alexis de Tocqueville, L'Ancien Régime et la Révolution, Paris, Gallimard, coll. «Folio», 1967, p. 43-44. 
somme annule l'individualité de ce phénomène. Lorsque nous détaillons trait par trait la nature d'un homme dont nous avons une image tout à fait unique, nous découvrons généralement que chacun de ces traits est plus ou moins universel et partagé par bien d'autres hommes. Le destin d'un individu, incomparable tant qu'il est considéré dans son ensemble, peut se décomposer en une somme d'événements dont chacun est en réalité très courant, ce qui est d'autant plus manifeste que les unités choisies sont plus petites $^{1}$.

Dès que l'on analyse un phénomène ou un individu dans le détail extrême, on peut trouver un grand nombre d'autres phénomènes ou d'autres individus qui partagent avec lui certains traits : par là, de singulier et de possiblement extraordinaire il devient ordinaire, du moins en partie, et réintègre le lot commun. L'extraordinaire n'est alors d'une part qu'une certaine configuration de la rencontre de plusieurs ordinaires, et il a d'autre part besoin de la forme conceptuelle qui met ensemble les particuliers ordinaires, il a besoin de la montée en généralité, de l'abstraction. Ne faudrait-il pas voir là un élément permettant de comprendre pourquoi nous peuplons les temps anciens de tant et tant de héros et de grandes actions, tandis que les époques proches, engluées dans les détails sus et pas encore oubliés, nous apparaissent toujours comme plus banales, échappant par les détails à la possibilité de ce que Simmel appelle «la forme supérieure qui les résume» et les constitue en ensemble individuel?

On peut écrire une histoire de cet événement extraordinaire que fut la Révolution française en mettant l'accent sur les ruptures politiques, juridiques, sur les changements de régime émotionnel. Si l'on choisit de ne pas adopter une telle méthode de compréhension historique dégagée de la succession des événements particuliers, on verra au contraire que, au sein même de ce que le concept saisit sous la forme de l'extraordinaire, persiste la multiplicité de l'ordinaire:

Quels que soient les événements, chacun continue de faire son métier accoutumé. On sème, on récolte, on fabrique, on vend, on achète, on consomme selon le besoin et l'usage [...]. Aux jours les plus sombres de la Terreur, vingt-trois théâtres prospéraient à Paris. On jouait l'Opéra de

1. Georg Simmel, La Forme de l'histoire et autres essais, Paris, Gallimard, coll. «Le Promeneur», 2004. p. 43. 


\section{Penser par extraordinaire}

Corisandre «avec ses agréments», des pièces sentimentales et bouffonnes; les cafés étaient pleins de monde, les promenades très fréquentées ${ }^{1}$.

Quelque chose se perd donc dans l'analytique rationnelle qui décompose les phénomènes pour les ramener à la mesure de l'ordinaire.

\section{RÉSISTANCE}

Un colloque, déjà évoqué, dont les actes ont été récemment publiés sous le titre L'Ordinaire et le politique ${ }^{2}$, a choisi de réfléchir sur l'ordinaire comme lieu de résistance, refusant de ne voir le transgressif que dans l'extraordinaire, et de ne laisser à l'ordinaire que la réaction et le conservatisme. Un ensemble de quatre articles, s'appuyant sur l'analyse philosophique ou artistique, s'attaque à l'ordinaire par le biais du refus des surplombs et de l'intellectualisme, qu'il soit conçu comme idéalisme métaphysique (auquel Laurent Bove, de compagnie avec Machiavel, Bruegel et Spinoza, oppose un retour à la nécessité de la chose-même comme puissance d'affirmation résistante) ou comme dogme politique. Bruce Bégout analyse la notion de common decency, par laquelle George Orwell désigne le sens moral des «gens ordinaires» comme né de la pratique et s'y exprimant, à l'écart de toute forme de pouvoir. Ce serait justement, pour la vie et la morale ordinaires, d'être ainsi anarchistes, à l'écart de la puissance et précisément ordinaires, qui permettrait en elles la conservation spontanée des valeurs de l'universel, la résistance, mais rendrait difficile toute politisation au sens partisan ou théorique. JeanJacques Rosat et Yann Moulier-Boutang, chacun à leur manière mais dans la proximité, tout en retrouvant les thèmes de la première partie, poursuivent d'une certaine manière l'argument en opposant l'acceptation du monde par l'homme ordinaire, dans une sorte de passivité sensible aux événements bouleversant le quotidien, et son imperméabilité aux dogmes irrationnels des politiques, qui ont plus de prise sur les esprits sceptiques.

1. Louis Bourdeau, L'Histoire et les historiens, 1888, p. 120-122, cité par Jacques Rancière dans Les Noms de l'histoire. Essai de poétique du savoir, Paris, Le Seuil, 1992, p. 14.

2. Dirigé par Claude Gautier et Sandra Laugier, Paris, PUF, 2006. Voir aussi l'entrée «L'ordinaire: platitude et scepticisme?» du présent dossier. 
Un second ensemble d'articles permet de dépasser l'anti-intellectualisme en s'attaquant à cette question de la résistance de l'ordinaire à partir d'une plus grande proximité avec la positivité des pratiques. Sur ce point, et quoique intéressante par ailleurs, l'analyse de Guillaume Le Blanc repense, avec Michel de Certeau, de manière assez attendue, la vie ordinaire comme jeu tactique au sein des normes détournées et non pas seulement lieu de leur reproduction. Stéphane Haber complexifie néanmoins le tableau en rappelant l'introduction par Habermas d'une dimension historique face à la notion husserlienne de «monde vécu». Le «monde vécu», au sens d'un arrière-plan sécurisant, ne peut fonctionner, selon Habermas, que pour les sociétés archaïques. Dans le monde moderne, les routines sont déstabilisées, du sein même de l'ordinaire, par des machineries complexes (dont le marché économique serait un exemple) produisant de l'innovation, du non-ordinaire, sans la coopération consciente des sujets (l'article de François Lebaron développe d'ailleurs ensuite ce modèle de l'ordre économique comme résultat non voulu, tout en en nuançant l'aspect par trop naturaliste). Dans le même temps, souligne Habermas, on a vu l'émergence d'une propension à la réflexivité sociale qui, à partir de l'échange langagier ordinaire, offrait des espaces de micro-inventivité. De l'ordinaire surgissent donc deux sphères, des «sphères structurées par la communication » et, en menaçant la vitalité mais les forçant aussi ainsi à entrer en visibilité par le biais de mouvements sociaux, des «sphères d'action formellement organisées». L'extraordinaire n'est pas, on le voit, le seul lieu du transgressif.

\section{DIEU}

Un problème typiquement médiéval, souvent traité, toujours considéré, naît de l'idée que Dieu ne peut être subsumé sous aucun universel - aucun genre, aucune espèce; qu'il ne participe à aucun accident. Qu'il n'est soumis à aucune loi naturelle, a fortiori à aucune loi rationnelle. Dieu est à l'origine de l'ordre des choses (il existait avant que les choses soient ordonnées) et continue de se situer en dehors de cet ordre. Il n'est pas soumis aux lois qu'il instaure, et dont il garantit la puissance. Or, la théologie médiévale considère à la fois que l'esprit humain est incapable de comprendre cet être dont les caractéristiques dépassent infiniment son 
domaine de juridiction, et qu'il est le seul à pouvoir le faire. Dans quelle mesure la structure naturelle de l'esprit est-elle capable d'accueillir et de contenir ce qui lui est par nature contraire? Ce problème central de la théologie est au cœur de la question de la compréhension du divin, où il s'agit non pas de dire le vrai sur Dieu - seul Dieu connaît sa vérité, ou plutôt: il est seul capable de l'entendre - mais de dire sur lui quelque chose de non-faux, de le saisir en quelque sorte.

Il est certain que Dieu est absolument in-soumis, in-dépendant, puisque rien ne lui sert de norme ni de cause. Il ne saurait donc se soumettre aux lois de l'esprit qui ramènent dans l'ordinaire les phénomènes les plus divers, les plus singuliers. Il ne peut y avoir de maîtrise de l'objet divin, dont la transcendance absolue exclut qu'on la comprenne, et dont la grandeur absolue exclut qu'on la circonscrive, même par l'esprit. Ce serait un péché d'orgueil que de croire que l'on peut saisir Dieu. Dieu est d'abord inaccessible à l'expérience: il échappe à toute caractérisation par son absence. Dieu est également inaccessible à l'imagination. Il est irreprésentable, pas seulement au sens pictural, mais surtout au sens de la représentation abstraite. Or, les esprits familiers des Catégories d'Aristote ne peuvent concevoir l'abstraction et le travail spéculatif en général que comme une classification des objets dans des cases. Mais Dieu n'entre pas dans les catégories ordinaires de l'esprit. Hors des lois de la nature, il se situe aussi hors des lois de l'esprit. Ainsi Dieu est un, contrairement aux créatures qui sont composées; il est un, mais il est en même temps trois. Il est partout et nulle part; il est éternel et sempiternel; il est omniscient et omnipotent; il n'a pas d'accidents, bien qu'il soit une substance, etc. Comment un tel objet pourrait-il être connu par le moyen des facultés ordinaires de la raison? Inversement, est-il possible que Dieu se soustraie à ces facultés, s'il veut être connu de la créature qui se révèle à lui?

La théologie devrait donc penser par extraordinaire, parce qu'elle s'ordonne à son objet extraordinaire. Ainsi la théologie dite révélée tientelle ses principes de Dieu lui-même; c'est une science proche de la science que Dieu a de lui-même. Par rapport à l'extraordinaire, elle adopte une position de soumission: elle l'accepte comme tel; elle adhère à l'extraordinaire, elle reste dans une dimension esthétique et contemplative. Par contraste, la théologie naturelle est plus problématique, parce que son objet naturel (la créature) et l'objet qu'elle veut se donner (Dieu) sont en contradiction. Il ne suffit pas de dire de Dieu qu'il est; la raison 
exige de savoir ce qu'il est (les caractéristiques de sa substance). Il faut prédiquer de Dieu, lui imposer des prédicats. Mais prédiquer de Dieu à l'aide du langage fait pour dire les choses ordinaires est délicat: il faut savoir si les signes linguistiques peuvent avoir Dieu pour référent, s'ils peuvent atteindre un signifié irreprésentable. La référence des signes peut-elle dépasser notre intention? Dans quel tréfonds secret de l'esprit trouveraient-ils alors leur signifié, si celui-ci existe? Même en postulant la communauté ontologique, la question de la prédication de l'extraordinaire n'est pas réglée. Si l'être est commun aux créatures et à Dieu, il n'a pas le même mode (modus essendi) - Dieu a l'être simple, les créatures l'être composé, dit Boèce dans ses Traités théologiques. L'être simple est ce qu'il est, alors que l'être composé se disperse toujours dans des accidents qui le rendent différent de lui-même, parce qu'ils l'attachent à des entités qui ne sont pas lui. Tenter de prédiquer l'être simple à partir du langage signifiant l'être composé, c'est tenter d'approcher l'un par le moyen d'un discours composé, multiple par nature. C'est à peu près aussi raisonnable que d'essayer de séparer un atome avec un couteau à pain. Il faut donc trouver une manière de prédiquer qui permette de dire quelque chose de Dieu, l'atteindre dans une certaine mesure, sans espérer saisir ce qu'il est. La prédication théologique peut alors prendre deux formes: la forme d'une conjecture d'éminence (qui dit de Dieu ce que l'on peut supposer qu'il est, étant donné sa supériorité intrinsèque, son ineffable unité, et l'incompatibilité de son essence avec tout défaut/manque) ou la forme d'une négation qui ne s'embarrasse d'aucune affirmation: s'il est impossible de dire ce qu'est Dieu, autant se borner à dire ce qu'il n'est pas. Ces deux démarches exploitent respectivement la communauté ontologique, et la différence ontologique.

Pour la théologie négative, les noms de Dieu ne peuvent être qu'équivoques. «On connaît mieux Dieu par l'inconnaissance que par la connaissance, et l'ignorance à son sujet constitue la véritable connaissance, car il est plus conforme à la vérité et à l'exactitude de nier Dieu en tout que de l'affirmer en tout ${ }^{1}$.» Cette théologie apophatique ne se risque pas, parce que rien de ce que nous disons de Dieu n'est propre: «Elle vise à écarter de Dieu quelque chose, plutôt qu'à dire ce qu'il est ${ }^{2} »$, considérant que tout ce que l'on peut dire de Dieu est équivoque; et

1. Jean Scot Erigène, Perpiphyseon (De divisione natura), $510 \mathrm{~B}$.

2. Thomas d'Aquin, Somme théologique I, q. 13, a. 2. 
quitte à être équivoque, autant l'être consciemment, parler de Dieu de façon oblique, en parlant d'autre chose que de lui. Puisqu'il est impossible de ne pas dire que Dieu est une substance, il est préférable de dire qu'il n'a pas d'accidents. À l'opposé, la théologie de l'éminence, cataphatique, exploite l'idée de transcendance divine pour appliquer au discours ordinaire la modalité de l'extraordinaire. Elle utilise le superlatif, le transfert des catégories, le remplacement du verbe avoir par le verbe être et autres transformations sémantiques, grammaticales et logiques. Elle exploite la transcendance de Dieu, en travaillant, du côté de la créature, sur ce qui est relatif à Dieu. Si Dieu dépasse en transcendance sa créature et s'il est impossible d'utiliser les outils ordinaires pour atteindre l'extraordinaire, il est néanmoins raisonnable de tirer des liens de causalité qui unissent manifestement la créature à son créateur une méthode pour conjecturer de la cause à partir de l'effet - autant à partir d'un principe de ressemblance qu'à partir d'un principe de dissemblance: c'est l'analogie.

\section{INDIVIDU}

L'individu (appelé personne quand il s'agit d'une substance rationnelle), c'est d'abord ce qui est indivis, qui forme un tout, numériquement un: c'est la plus petite unité possible au sein d'un universel, l'unité distincte des autres unités, le «non séparé en soi, mais séparé de tous les autres ${ }^{1} »$. L'individu est donc à la fois pris dans un universel qu'il incarne (Socrate incarne l'humanité: c'est une substance, un substrat qui porte l'universel et les accidents), et une unité distincte irréductible aux autres unités, fondamentalement différente (singulière). L'individu s'inscrit et se désinscrit dans l'universel. Ce qui singularise l'individu au sein de l'universel, cela ne peut être que ses accidents particuliers - puisque sa substance est la même que celle de tous les individus qui ne lui ressemblent pas. Le caractère extraordinaire ne peut donc venir que d'aspects qui ne sont pas essentiels en l'individu: en ce sens, il ne peut pas y avoir d'extraordinaire en soi, mais seulement accidentel.

1. Thomas d'Aquin, Somme théologique I, q. 29, a. 4c. 
Dans la classification des êtres de Porphyre (son $a r b r e e^{1}$ ), qui reprend celle de la Métaphysique d'Aristote, ce sont en effet les différences accidentelles, attachées à la matière, qui distinguent les individus entre eux. Chaque substance est une composition de forme et de matière accidentée (materia signata): grâce à la matière désignée, la forme est individuée. Connaître une substance, c'est en cerner la quidditas, quiddité, composée de l'universel et du particulier. Mais s'il n'y a de science que du général, si l'on ne peut connaître une substance qu'en passant par la considération de sa forme, le particulier est-il connaissable? Provisoirement, on a pu répondre que ce n'est pas seulement par expérience que l'esprit connaît les différences accidentelles. Les accidents peuvent eux-mêmes être abstraits et considérés sous un angle universel: ainsi, d'un individu bon, on dit qu'il possède la bonté et y participe, comme toutes les choses bonnes. La bonté est prise absolument, indépendamment de toutes les choses bonnes. On pourrait donc connaître les individus dans leur forme particulière en rapportant la particularité à une généralité quelconque. Mais comment dire, alors, que ce sont les accidents qui distinguent les individus entre eux, si les accidents rassemblent aussi les individus en autant de classes? Et comment conserver l'idée d'indivisibilité, si les individus peuvent encore être séparés en bons, forts, coléreux, musiciens, etc.? «La structure de l'énoncé de définition étant la détermination progressive de la matière générique par les différences qui sont les contrariétés du genre en question, la dernière différence atteinte, en tant que terme indivisible et point d'arrêt auquel aboutit la division des concepts, est celle qui dit enfin l'identité; car, au-delà de ce terme, on le pressent comme un abîme, il ne restera plus que la multiplicité indéfinie, éparse, de l'in-forme et donc de l'inconnaissable ${ }^{2}$.» L'individu dont on a l'expérience est-il connaissable en tant que tel? ou sont-ce ses différences qui sont connues, parce que concevables comme autant d'espèces? L'identité de l'individu apparaît à la pensée classifiante comme une possibilité menaçante de l'extra-ordinaire, du hors-la-loi.

Guillaume d'Ockham démontre l'impossibilité de connaître le singulier autrement que par intuition ${ }^{3}$. L'individualité de la chose ne peut d'abord être saisie que par intellection intuitive de la chose, c'est-à-dire

\footnotetext{
1. Voir Porphyre, Isagoge, Paris, Vrin, 1998.

2. François Jullien, Si parler va sans dire, Paris, Le Seuil, 2006, p. 132-133.

3. Guillaume d'Ockam, Quaestiones in libros physicorum aristotelis, q. 7.
} 
sans chercher ni le principe de cette individualité, ni la différence ontologique contenue dans la substance. Tout singulier est extraordinaire, parce qu'indivis, il n'est rapporté ontologiquement à aucun ordre : le monde est composé de singuliers, et l'universel n'est que le produit d'une abstraction de l'esprit humain. Aussi est-ce une erreur de vouloir le connaître par référence à un ordre universel qui lui préexisterait. Pour Guillaume d'Ockham, on ne peut penser l'individu en tant que tel que par extraordinaire, c'est-à-dire en évitant de confondre les catégories de l'esprit avec les catégories de l'être. Si nous avons tendance à rapporter l'appréhension du singulier à des principes de classification internes à notre esprit, l'une ne dépend pas pour autant de l'autre, mais l'inverse: c'est à partir de la connaissance du singulier que nous forgeons des classifications universelles. On ne peut pas penser l'extraordinaire en le rapportant à un ordre, car l'ordre intramental vient justement de la connaissance de l'extraordinaire, c'est-à-dire du singulier appréhendé comme singulier. Il faut donc penser par extraordinaire pour pouvoir penser l'ordinaire; approcher les substances sans a priori. Mais Guillaume d'Ockham ne résout pas l'aporie: car la perception du singulier, qui permet une connaissance intuitive de l'individu, ne nécessite-t-elle pas, pour l'analyser, des concepts universels et généraux?

\section{HAPAX}

Voici l'hapax: un mot (ou une expression) apparu quelque part dans une œuvre et qui, par la suite, ne revient jamais. Pour l'exégète, il est porteur d'un sens auquel il est difficile de donner de l'ampleur ou d'élargir son extension, parce qu'il a été écrit mais a aussi été abandonné. On peut s'attarder sur sa rareté, sur son apparition éphémère; mais peut-on décemment fonder sur lui une interprétation positive? L'importance qu'on lui conférerait ne serait-elle pas en raison inverse de celle que l'auteur lui a donnée ? Voilà donc un extraordinaire qui ne l'est que pour et par l'œil de l'interprète, un extraordinaire étique: il n'est hors-l'ordinaire que pour le lecteur qui a une vision globale de l'œuvre, leste artificiellement les termes d'un poids exégétique et cherche dans le texte de quoi confirmer ses intuitions. Les mots n'ont pas la même importance pour l'écrivain et son lecteur. 
Il est d'autant plus difficile de saisir la teneur de l'hapax que l'auteur ne s'explique évidemment pas sur sa rareté. Tout discours sur l'hapax reviendrait à le nier comme tel, puisqu'il doublerait son occurrence.

A priori, l'étude d'un hapax sert à prouver, puis à comprendre l'absence ou la rareté d'un thème dans une œuvre. Mais le lecteur est toujours enclin à aller plus loin: car ce n'est pas d'absence qu'il s'agit, mais de rareté: l'hapax est un cas unique qui suscite ses fantasmes: car un monde de possibles s'ouvre avec l'apparition du mot, sur lequel il s'attarde comme au bord du double-fond d'une œuvre apparemment univoque. On oscille alors entre l'exigence de se tenir éloigné de toute surinterprétation, en lisant la rareté de l'hapax comme le signe d'un abandon par l'auteur, d'une mise à l'écart, et le désir de voir dans le sublime isolement d'un mot un procédé destiné à en valoriser le surgissement, voire tout simplement, un enthousiasme d'exégète pour cette rareté même, avec l'idée qu'elle recèlerait, de manière cachée, ce que tout le déploiement évident ne parviendrait pas à dire, qu'elle aurait d'autant plus à nous révéler qu'elle serait hors l'ordinaire du texte. L'unique renvoie au négligeable, mais aussi à son contraire, à l'extraordinaire.

Bref, on se pose des questions:

- ce mot est-il révélateur d'une orientation (scientifique) de l'auteur, envisagée puis abandonnée, mais qui a manifestement laissé ses traces et doit ainsi être considérée comme significative pour l'œuvre entière? (il le dit une fois, donc il l'a pensé, donc il le pense);

- ce mot est-il révélateur du rejet ou du désintérêt pour une orientation (scientifique), sur lesquels on peut fonder l'hypothèse d'un intérêt ou d'une adhésion pour l'orientation opposée? (il ne le dit qu'une fois, donc il ne le pense pas, donc il pense le contraire);

- ce mot est-il à considérer comme un accident, sur lequel on n'a rien à dire qu'à le signaler? (il ne le dit qu'une fois, donc on ne peut rien en tirer).

L'hapax est-il donc ce qui, échappant à l'ordinaire du texte et à ses règles déjà parcourues, prouvées, visitées et revisitées de mille façons, remet en question ces mêmes règles, exige de trouver une autre règle, de redéfinir tout un style? ou n'est-il, comme le monstre dans la nature, qu'un fait rare duquel il faut se garder de tirer des conclusions? Diderot, que l'on pourra entendre ici et comme philosophe de la nature et comme critique d'art appelant à se garder de la sur-interprétation, rappelait ainsi, dans Le Rêve de d'Alembert que «l'homme n'est qu'un effet commun, le 
monstre qu'un effet rare; tous les deux également naturels, également nécessaires, également dans l'ordre universel et général [...]. Tous les autres circulent les uns dans les autres, par conséquent toutes les espèces... tout est un flux perpétuel». L'être humain normal est simplement plus fréquent que le monstre. L'extraordinaire n'a peut-être pas toujours beaucoup à nous dire. S'il déclenche nos rêves, nos fantasmes, il est peut-être moins intéressant pour l'exégète ou le naturaliste que la recherche des formes ordinaires, des lois constantes du texte ou de la nature.

\section{MYSTÈRE}

Il n'y a pas d'une part un monde de l'ordinaire et du quotidien, et de l'autre un monde extraordinaire échappant à ses règles. Il y a rencontres, organisées (sous la forme du rite, le sacré s'instille dans l'ordinaire profane) ou subies (comme surgissement). L'extraordinaire n'est pas apprivoisé (normalisé) par le rite: mais le profane contient le sacré au sens où il en contient la voie d'accès. Toute quotidienneté peut alors accueillir en elle le sacré et y donner accès: le centre du monde est partout, et il suffit, comme Mircea Eliade, d'en souligner la place dans la géographie sacrée pour faire d'un lieu un passage.

Dans un monde religieux, l'inexplicable au premier abord est ramené au mystère de Dieu et le quotidien se peuple alors des traces de son dialogue avec l'au-delà, le rite lui-même empreint le quotidien d'un extraordinaire proche et doux. Dans un univers de lois rationnelles, l'inexplicable ne peut au contraire qu'être terrifiant. C'est sur une telle conjonction de l'ordinaire, du quotidien, et d'un extraordinaire qui ne peut être rapporté à aucun divin, que joue le roman fantastique. C'est pourquoi les peurs littéraires qu'il suscite apparaissent à la fin du XVIII ${ }^{\mathrm{e}}$ siècle et au début d'un XIXe terrifiant sur fond d'un quotidien privé de Dieu.

Chez les auteurs d'inspiration chrétienne au contraire, même à l'époque contemporaine, souligner l'extraordinaire ne provoque aucune angoisse, plutôt la joie d'un accès à ce que la vie matérielle, les choses profanes ravissent. Ainsi Éric Rohmer, dans Ma nuit chez Maud, semblet-il souligner avec bonheur cette échappée soudaine aux lois de la sociologie qui éloignent les individus vivant dans des univers sociaux différents. 
Soudain, l'extraordinaire hasard laisse ressurgir le sentiment, l'amitié, fait échapper au profane, sans peur, bien au contraire: dans un café à Clermont-Ferrand, le personnage principal de l'histoire, qui est aussi le narrateur et a pour caractéristique sociale de fréquenter les églises plus que les cafés, rencontre un ami à lui, Vidal, communiste convaincu, qu'il n'a pas vu depuis longtemps, et pour cause. À ce dernier, qui s'étonne de leur rencontre, dans un lieu où ni l'un ni l'autre n'ont leurs habitudes, il rétorque: «Nos trajectoires ordinaires ne se rencontrant pas, c'est dans l'extraordinaire que se situent nos points d'intersection: forcément ${ }^{1}$ !»

\section{CONTRE LA MÉTHODE?}

«Toute la méthode ne consiste qu'à disposer en ordre toutes les choses vers lesquelles doit se tourner la vue de l'esprit, pour que nous trouvions quelque vérité 2 .» Si par cette formule Descartes agrège l'ordre et la méthode, il ne fait pas de celle-ci un procédé figé, une procédure commode, systématique, inapte à saisir le réel dans sa complexité. Il tient une position très nuancée que révèle une lettre à Mersenne de mars $1637^{3}$, d'après laquelle la méthode consiste «plus en Pratique qu'en Théorie»: elle n'est pas un protocole universellement applicable, mais l'expression de la démarche rationnelle personnelle que nécessite toute quête de vérité. On ne connaît pas en inventoriant les références historiques, en comptant les opinions, et en maquillant les ignorances par des mots vides de sens; de même que l'on ne voit pas avec les yeux d'autrui, l'on ne peut penser qu'avec son propre esprit. Il est donc nécessaire de connaître les actes intellectuels producteurs de science, et de déterminer le meilleur ordre pour ses propres opérations. Telle est la double fonction de la méthode. Celle-ci s'appuie sur un ordre déductif. Soit une question comportant un point que l'on ignore. La méthode permet de voir comment cet élément peut se déduire des données en notre possession. Elle est ainsi l'instrument de l'extraordinaire, qui désigne pour

\footnotetext{
1. Paris, Petite Bibliothèque des cahiers du Cinéma, 1969, p. 69

2. René Descartes, Règles utiles et claires pour la direction de l'esprit en la recherche de la vérité, La Haye, Martinus Nijhoff, 1977, p. 16.

3. Lettre de Descartes à Mersenne de mars, 1637, A.T., I, p. 349.
} 
Descartes ce qui nous était inconnu et qui constitue une nouveauté en matière de science.

L'extraordinaire, dont la méthode est l'instrument, est lui-même un ingrédient de la pensée qui, telle une chasseresse, peut toujours connaître plus et mieux. Instrument d'une science qui est un art de la recherche et de l'invention, la méthode participe en effet de la promotion de la découverte scientifique et de l'inscription de celle-ci dans une perspective générale d'avancement des savoirs. Les deux derniers paragraphes de la seconde partie du Discours de la méthode soulignent ainsi que le recours à une raison méthodique a permis à Descartes de faire des progrès rapides dans les domaines de l'analyse géométrique et de l'algèbre. Doublement productive en matière de science, elle fait avancer dans le savoir et donne de la science l'image d'un domaine en devenir, dont la complétude est nécessairement toujours à venir. Dans cette perspective, l'extraordinaire n'est plus ce qui paraît tel, ce qui échappe à la compréhension, mais au contraire ce dont l'admirable complexité est saisie par l'esprit, grâce à l'analyse méthodique.

\section{Anomalie}

La qualification d'anomalie résulte de la coexistence problématique, au sein d'un même ensemble, d'un certain nombre de paramètres qui en assure la cohésion, et d'autres traits tout aussi saillants qui menacent d'en rompre la cohérence. Cet oxymore rétif à toute classification déroute, irrite parfois, parce qu'il ébranle le déroulement logique d'un raisonnement bien huilé, habitué à penser par la ressemblance et le déjà vu, selon un mouvement de va-et-vient entre le particulier et le général. Les règles ne peuvent plus être appliquées, et le mécanisme d'administration de la preuve se grippe. Mais pour qui accepte de ne pas reléguer l'anomalie dans l'anormal, le marginal ou le délétère ${ }^{1}$, pour qui refuse d'évacuer le différent au profit du même, l'anomalie présente une vraie valeur heuristique: la conscience du désordre contraint l'ordre à se réformer. Mais la dynamique de l'extraordinaire par l'ébranlement des catégories n'est pas acceptable par tous les types d'ordre. En médecine, l'anomalie

1. La mise en évidence de cette tendance dessine une des grandes lignes de force de l'œuvre de Michel Foucault. 
(la pathologie), opposée au normal, appelle une intervention visant à l'éradiquer, sous peine de mettre en péril l'organisme du malade. Si elle ne présente pas une menace de mort, elle est au mieux une imperfection débilitante ou stigmatisante. La médecine et certains types de régimes politiques exercent à l'égard de l'anomalie une pression normalisante; ces arts visent l'instauration d'un ordre prescriptif, dans le sens où ils ne se prononcent pas sur ce qui est, mais sur ce qui doit être. Le fait s'ordonne alors au droit.

Dans l'Espagne moderne, on voyait dans les minorités religieuses une anomalie du corps social susceptible de mettre en péril sa cohésion ${ }^{1}$. La différence confessionnelle rendait caduque le principe d'unité de la foi et risquait de détourner la bienveillance divine d'un peuple espagnol à la loyauté imparfaite, le vouant ainsi aux éternelles gémonies ${ }^{2}$. À l'argument théologique, s'adjoignaient des réflexions d'ordre politique ancrées dans un passé mythique forgé sur la dialectique destruction/restauration propre à la Reconquista. Les Espagnols du XVII siècle soupçonnaient ainsi volontiers judaïsants et mahométants d'ourdir des complots visant à entraîner la désagrégation de la société. Or, ni les juifs ni les musulmans n'ont à proprement parler alimenté cette hantise du dépérissement du corps social, à l'inverse des conversos, ces nouveaux chrétiens suspectés de persévérer en secret dans l'hétérodoxie. La notion d'anomalie se précise au prisme de cette obsession du décryptage dont l'Inquisition s'imposa comme l'orchestratrice majeure: le danger de l'anomalie réside précisément dans sa troublante ressemblance avec l'orthodoxe, le normal, malgré une irrémédiable différence qui est au prime abord invisible. L'anomalie n'est pas un autre, un alter, mais un différent imbriquant le soi et l'autre, l'identique et son contraire, le conforme et le difforme. Très répandu, le thème du traître cristallise cette ambiguïté : pour trahir, il faut avoir été solidaire de ceux auxquels on nuit et avoir renié ce qu'on est ${ }^{3}$. Cette inquiétante étrangeté a généré une

\footnotetext{
1. Henry Méchoulan, «Constitution de l'antimachiavélisme: le Dieu des antimachiavéliens espagnols du siècle d'or», dans Henry Méchoulan, L'Antimachiavélisme de la Renaissance aux Lumières, Paris, Hachette, 1989.

2.Idem, Le Sang de l'autre ou l'honneur de Dieu. Indiens, juifs et morisques dans l'Espagne du Siècle d'Or, Paris, Hachette, 1979.

3. Voir la communication de Bernard Vincent, «Les morisques et la trahison », dans Bernard Lavallé et Pierre Civil (dir.), actes du colloque international Patrie(s) et nation(s) dans l'Empire espagnol des Habsbourg, 18-19 mai 2006.
} 


\section{Penser par extraordinaire}

logorrhée consacrée à l'extirpation de l'anomalie conversa, conçue tantôt comme un corps étranger, tantôt comme une partie malade du corps, oscillant entre le génocide, l'ethnocide et l'expulsion' ${ }^{1}$.

Quand c'est un individu qui constitue l'anomalie, il cristallise des mouvements et des courants qu'il révèle dans un agencement original. Un personnage comme Menocchio ${ }^{2}$, ce meunier frioulan du XVI ${ }^{\mathrm{e}}$ siècle, chamboule les cadres de raisonnement établis dans les sciences humaines, ébranle un socle non problématique jusque dans les années 1970, en révélant la vanité d'une rupture entre culture populaire et culture savante. En effet, Menocchio, puisant dans le Décaméron, le Fioretto della Bibbia ou dans les Voyages de Mandeville, forge sa propre culture qui tire sa forme originale du terreau populaire sur lequel elle s'enracine. Le titre de l'ouvrage de Ginzburg, Le Fromage et les vers, se fait l'écho de la conception bien personnelle du monde que soutient Menocchio. Écoutons-le expliquer la genèse:

Au commencement, ce monde n'était rien que de l'eau de mer. Elle fut barattée et elle a caillé comme un fromage. Et de ce fromage sont nés des vers en quantité. Et ces vers sont devenus des hommes dont le plus puissant et le plus savant a été Dieu³.

Nous avons ici affaire à une forte porosité et à une contamination réciproque entre deux versants de la «culture» qu'habituellement les historiens contemporains de Ginzburg séparaient, avec pour résultat l'émergence de configurations singulières et uniques. Les catégories et les outils à la disposition de l'historien, soigneusement élaborés pour lui permettre de s'emparer de son objet et partant, de construire un discours le rendant intelligible, se dénudent dans tout leur arbitraire. Il faut bien admettre que ces schèmes que l'on croyait neutres (parce qu'impensés)

\footnotetext{
1. Voir, entre autres, José María Perceval, Todos son uno. Arquetipos, xenofobía y racismo. La imagen del morisco en la Monarquia española durante los siglos $\mathrm{XVI}^{\mathrm{e}}$ y XVII ${ }^{\mathrm{e}}$, Almería, Instituto de estudios almerienses, 1997; Vincent, Bernard, «L'expulsion des morisques», dans Ernest Belenguer Alcalá-Zamora (dir.), Calderón de la Barca y a España del Barroco, Madrid, Centro de Estudios políticos y constitucionales, 2001, t. I ; Juan Ignacio Pulido Serrano, «La expulsión frustrada. Proyectos para la erradicación de la herejía judaica en la Monarquía hispana», dans Francisco José Aranda Pérez (dir.), La Declinación de la monarquía hispánica en el siglo XVII, Cuenca, Ediciones de la Universidad de Castilla-La Mancha, 2004.

2. Carlo Ginzburg, Le Fromage et les vers. L'univers d'un meunier du XVI' siècle, Paris, Flammarion, 1980.

3.Ibidem, p. 91.
} 
résultent d'une construction historiquement située et contingente. Ainsi, le clivage savant/populaire suppose qu'on parte d'un découpage socioprofessionnel préétabli pour assigner $a$ priori à des groupes sociaux des matériaux culturels «spécifiques».

En indexant irrémédiablement les différenciations culturelles au cloisonnement de la société en catégories, l'opposition entre savant et populaire apparaît comme un avatar de l'idéal de totalisation instauré par Fernand Braudel, qui prétend articuler des agrégats de dimension intermédiaire pour reconstruire une globalité. Or, le lien entre de tels agrégats qui, parce que préconçus, empêchent l'adéquation des outils épistémologiques à une problématique, demeure un point aveugle de la démarche historienne. La valeur heuristique de l'anomalie recouvre alors toute sa force: en posant une injonction logique, elle contribue à redéfinir un champ historique dès lors plus apte à appréhender l'extraordinaire anomalie des acteurs. Dans le cas de Menocchio, la pertinence de la notion d'appropriation en histoire culturelle conforte un versant historiographique neuf, qui mêle histoire du livre, critique textuelle, histoire des identifications. Roger Chartier propose ainsi d'échapper au carcan d'une conception sociographique de la culture et de partir des objets euxmêmes pour retracer les espaces sociaux hétérogènes où circulent textes et normes culturelles ${ }^{1}$. Ce faisant, il implique d'autres facteurs de différenciation (appartenance religieuse, sexuelle, ou générationnelle...) rendant compte de la complexité dynamique du social. Un glissement d'une histoire sociale de la culture à une histoire culturelle du social s'opère alors, entraînant une reconfiguration interne à la discipline historienne et montrant qu'on peut analyser le «populaire» autrement que par des études quantitatives et sérielles qui en gomment spécificités et aspérités.

Mais, l'anomalie Menocchio recèle encore bien des enseignements. En effet, Ginzburg a «rencontré» son personnage à travers les archives de l'Inquisition qui a instruit un procès contre le meunier frioulan. Le terrain se déplace ainsi de la simple découverte d'un témoignage de culture populaire à une arène où luttent les tenants d'une culture des élites, dominante, «orthodoxe», et un individu qu'on tente de ramener dans la norme. Deux nouveaux déplacements s'imposent donc en histoire culturelle et

1. Roger Chartier, «Le monde comme représentation», Au bord de la falaise, Paris, Albin Michel, 1998. 
plus largement pour la discipline historienne. Le phénomène d'appropriation tel que Menocchio permet de l'appréhender, brise le clivage artificiel opposant la réception/production des œuvres donnant la mesure du processus d'invention et de «braconnage» de l'homme ordinaire que Michel de Certeau a bien mis en évidence dans L'Invention $d u$ quotidien $^{1}$. L'anomalie-Menocchio institue une contre-tendance dans la discipline historienne en levant l'opposition entre une objectivité supposée des structures et la subjectivité des représentations car celles-ci participent de la construction ou de la redéfinition de soi par rapport aux autres².

Autre exemple bien connu, jusqu'à la dérision de On connaît la chanson: les chevaliers-paysans du lac de Paladru³ ${ }^{3}$, qui, replacés dans les cadres conceptuels qui articulent la pensée de «la société médiévale», posent une énigme. Où situer ce groupe au sein de la tripartition établie par les historiens ${ }^{4}$, séparant les oratores, les bellatores et les laboratores ${ }^{5}$, et interdisant recoupements ou télescopages dans une logique d'altérité radicale et de complémentarité? Ce type d'anomalie qui diffère de celle de Menocchio en ce qu'elle concerne un groupe et non un individu, et en ce qu'elle ne s'inscrit pas dans une problématique de la déviance, n'en est pas moins dérangeante en ce qu'elle défie le principe de différenciation des catégories sociales que sous-tendrait une «mentalité» médiévale 6 . Si cette anomalie n'implique pas une remise en cause totale de ces schèmes que les contemporains eux-mêmes ont forgés et que l'énonciation et la théorisation ont contribué à imposer dans les faits ${ }^{7}$, il n'en demeure

1. Michel de Certeau, L'Invention du quotidien, t. I, Arts de faire, Paris, 10/18, 1980.

2. Roger Chartier, « Le monde comme réprésentation », op. cit., p. 78.

3. Michel Colardelle et Éric Verdel (dir.), Les Habitants du lac de Paladru dans leur environnement.

La formation d'un terroir au XIe siècle, Paris, Maison des sciences de l'Homme, 1994.

4. Georges Duby, Les Trois Ordres ou l'Imaginaire du féodalisme, Paris, Gallimard, 1978.

5. Les textes qui offrent cette présentation tripartite foisonnent. L'un des plus connus est certainement celui d'Adalbéron de Laon dans son poème au roi capétien Robert le Pieu vers 1030. La bibliographie traitant de la structure de la société médiévale est abondante. Pour une présentation synthétique, on pourra se reporter à Jacques Le Goff (dir.), L'Homme médiéval, « introduction », Paris, Le Seuil, 1989 ; voir aussi, du même auteur, le chapitre «La société chrétienne ( $\mathrm{X}^{\mathrm{e}}-\mathrm{XII}^{\mathrm{e}}$ siècle), dans La Civilisation de l'Occident médiéval, Paris, Flammarion, coll. « Champs», 1982.

6. Pour en rester à la société médiévale, on trouve d'autres anomalies correspondant à une problématique similaire à l'instar des prêtres-soldats et des ordres militaires. La spécificité de ces derniers s'émousse à l'époque moderne, en perdant la dimension concrète de la réalité militaire. Ainsi, les Trinitaires et les Mercédaires se spécialisent dans les procédures complexes de rachat des captifs dans un espace méditerranéen disputé où sévissent corsaires et barbaresques.

7. Pour l'explicitation de cette logique de domination symbolique, voir notamment Pierre Bourdieu, $\mathrm{La}$ Distinction. Critique sociale du jugement, Paris, Éditions de Minuit, 1979. 
pas moins que le changement radical de perspective consistant à analyser des processus et des relations plutôt que des ensembles, renouvelle le traitement des catégories sociales dont l'emboîtement ne constitue plus la « société ${ }^{1}$. Contre la démarche monographique qui cherche à confirmer une hypothèse générale à travers son application dans un ancrage territorial déterminé, et grâce à une analyse des interactions entre les acteurs et le contexte spécifique où ils évoluent, on a su restituer la singularité des chevaliers-paysans de Paladru. Tout d'abord, en imposant dans le processus de recherche une orchestration pluridisciplinaire où différents champs apportent des informations que chacun est le seul à pouvoir fournir. Ainsi les fouilles de Charavines ont mis à contribution les apports conjoints de l'archéologie terrestre et subaquatique, de la sédimentologie, de la palynologie (le pollen conservé permet de reconstituer le paysage végétal), de l'ichtyologie (l'analyse des écailles a restitué la saisonnalité des captures de poissons), de la numismatique, de la dendrochronologie (méthode de datation fondée sur le comptage et la morphologie des anneaux de croissance des arbres). Mais le télescopage inédit des fonctions de chevaliers et de paysans que subsument les colons de Charavines et dont attestent les restes d'équipements guerriers recueillis sur le site, incite aussi à repenser les rapports entre temps et espace, via un détour par la géographie. Les chevaliers-paysans cristallisent une expression singulière de l'interaction entre les hommes et leur milieu à un moment donné, en pointant l'adéquation entre une configuration sociale et son environnement.

Or, cette anomalie exclut une conception fonctionnaliste de l'espace que faisait sienne un certain versant de l'historiographie sous l'égide de Lucien Febvre. Formalisée dans l'ouvrage La Terre et l'évolution humaine, introduction géographique à l'histoire ${ }^{2}$, cette conception assimilait la région naturelle à un réservoir de possibilités pour une société qui en activait certaines, indépendamment de tout déterminisme. Les chevalierspaysans montrent au contraire que, même s'ils mettent à profit leur environnement en gardant une marge d'action et une part d'invention conséquentes, les hommes subissent dans une certaine mesure les contraintes

1. Mauricio Gribaudi, «Les discontinuités du social. Un modèle configurationnel», dans Bernard Lepetit, Les Formes de l'expérience. Une autre histoire sociale, Paris, Albin Michel, 1995.

2. Lucien Febvre, La Terre et l'évolution humaine, introduction géographique à l'histoire, Paris, Albin Michel, 1922. 
de leur milieu. Dans notre exemple, ils ont résolu la question de l'autarcie et le problème de l'instabilité d'une zone-frontière menacée par des incursions ennemies. Cette part d'invention, qui défie les schèmes mentaux de hiérarchisation de la société médiévale en «inventant» une hybridité des fonctions à laquelle ils n'auraient pas eu recours dans d'autres circonstances, est le signe même des contraintes qu'impose un milieu. Ce constat invalide dans ce cas une explication fonctionnaliste du rapport à l'espace. Cette hybridation qui articule l'économie, la société, la civilisation en fonction d'un cadre géographique n'a rien d'arbitraire puisque les chevaliers-paysans sont exclusivement associés à Charavines.

L'anomalie des chevaliers-paysans de Paladru suggère donc de pratiquer une «géographie du passé», et impose de réfléchir aux rapports entre histoire et géographie sans annuler la spécificité de chacune. Une telle confrontation entre ces deux lieux de savoir a pu tourner au dialogue grâce aux travaux de Bernard Lepetit qui s'appliquent bien au déchiffrement de l'énigme proposé par les colons de Charavines ${ }^{1}$. Insistant sur l'historicité des systèmes spatiaux et plaidant pour la construction de modèles dynamiques pour que la «géographie du passé» ne soit pas un «arrêt sur image» évacuant la temporalité dans une saisie de l'espace, il propose de considérer un espace comme «le jeu des actualisations possibles des formes passées d'organisation de l'espace en combinaisons nouvelles. [...] Chaque segment de l'évolution historique ouvre la possibilité de nouvelles combinaisons, en empêche d'autres² ${ }^{2}$.

Ainsi, l'anomalie, par la tension qu'elle introduit entre le même et l'autre, contraint de penser par extraordinaire en remodelant, de l'intérieur, les champs disciplinaires, soit par une reconfiguration interne de ses versants comme l'a montré la figure de Menocchio, soit par un dialogue entre disciplines passant par un décloisonnement raisonné. Cette démarche revendique la valeur heuristique de l'écart et se prête au jeu de la désagrégation, du démembrement (provisoire?) de la pensée.

1. Bernard Lepetit, Les Villes dans la France moderne (1740-1840), Paris, Albin Michel, 1988; et Carnet de croquis. Sur la connaissance historique, Paris, Albin Michel, 1999. Voir en particulier le chapitre «Espace et histoire», p. 129-141.

2. Carnet de croquis. Sur la connaissance historique, op. cit., p. 140. 


\section{GenS SANS HISTOIRE}

Prenons le cas de l'anachronisme: dans les études historiques, l'attention à l'anachronisme concerne le plus souvent les mondes sociaux intellectuels et plus généralement des élites - ceux dont on peut penser que, par leur différence, ils ont créé du nouveau et fait basculer un moment historique (ou que du moins ils auraient pu le faire). Là, on trouve des biographies de précurseurs, des citations incongrues, une réflexion sur ce qu'a pu signifier un auteur marginal à son époque. Soit par exemple le cas de Mably: peu publié avant sa mort et assurément pas entendu, il a été lu par la Révolution comme un de ses pères annonciateurs. «Ses jugements lucides sur la politique de son temps lui ont permis d'anticiper la Révolution $^{1} »$, pouvait-on encore lire récemment à son sujet. Un tel auteur est ainsi à la fois maintenu dans son écart et pensé comme s'inscrivant dans son temps, au point même d'en exprimer le plus intime, les germes profonds porteurs d'avenir. Son extraordinaire «préscience», sa différence, intéresse les historiens.

Si l'attention à l'extraordinaire comme anachronisme est possible dans le monde des grands et des génies, une même prise en compte est nettement moins évidente pour les faits, gestes et paroles des «gens ordinaires». Tout se passe souvent comme si les individus populaires étaient voués, par définition, à une réintégration dans la moyenne ou la norme - sauf à surgir dans le registre de l'excès, du révolutionnaire ou du brutal, sauf à être des Damien portant le poignard contre Louis XV, des Mandrin dressant des armées de gueux contre l'ordre de ce même roi, ou des Pierre Rivière assassinant leur famille. Alors, cet excès est le plus souvent jugé avoir porté ses sujets aux portes de la folie. Comme si, des gens ordinaires, ne pouvait surgir aucune évolution historique, comme s'ils ne faisaient pas partie de ceux qui font l'histoire - sinon par leur nombre menaçant. Comment penser l'individu populaire extraordinaire?

Le Menocchio de Carlo Ginzburg ne peut absolument pas être compris comme «un individu médiocre, en lui-même privé de relief et pour cette raison précisément représentatif ${ }^{2} »$. Néanmoins, de son «cas limite»,

1. Jean-Luc Malvache, compte rendu de Hans Erich Bödeker et Peter Friedemann (éd.), Gabriel Bonnot de Mably: Politische Texte 1751-1783, revue Nomos, 2000. Souligné par nous.

2. Le Fromage et les vers. L'univers d'un meunier du XVI siècle, Flammarion, 1980, p. 16. 
absolument fascinant, extraordinaire, qu'il sait et dit tel ${ }^{1}$, Ginzburg veut tirer le plus de conclusions générales possibles. À la manière de Paul Veyne, il l'utilise comme différence provocatrice d'étonnement et de reconfiguration de nos idées sur un monde passé, comme moyen de transformer notre regard sur les rapports entre la culture populaire et la culture des élites au XVI ${ }^{\mathrm{e}}$ siècle. Mais l'extraordinaire finit bien ici par voir son statut érodé: il n'est plus extraordinaire que pour celui qui ne voit le passé qu'avec les yeux de son présent, sans en comprendre la logique. L'opération historienne n'a-t-elle alors pour finalité, en retissant la logique du passé, que de nous en rendre sensible la banalité ? Il est tentant de repousser l'extraordinaire populaire comme peu scientifique, suspect en somme. Reste que, comme tel, il peut avoir une forte valeur heuristique, à condition justement de lui conserver sa part de provocation et d'anachronisme, sans chercher à toute force à l'enrégimenter, à le réintégrer dans une logique majoritaire.

\section{ENTRE-DEUX}

Diderot, Réfutation d'Helvétius: l'originalité du génie ne s'explique pas par «l'éducation, ou le hasard des circonstances». Le véritable «être original» a un «caractère» qui «tranch $[\mathrm{e}]$ fortement avec celui des autres hommes», et ne «ressembl[e]» à rien de ce qui l'a précédé. L'originalité serait ainsi une disposition innée, et qui au demeurant s'exprimerait par la conjonction d'éléments jugés incompatibles. Celle propre à Shakespeare résiderait, toujours selon Diderot, dans «le mélange extraordinaire, incompréhensible, inimitable de choses du plus grand goût et du plus mauvais goût ${ }^{2} »$. Elle s'expliquerait ainsi par l'entrechoquement de jeux de scènes et de discours disparates et s'inscrirait dans deux séries, deux systèmes de règles, ou du moins deux sommes de prescriptions, renvoyant à un cadre théorique, le genre comique et le genre tragique, qu'elle réussirait à appliquer et, en même temps, bouleverser.

Cette idée que le génie est celui qui transcende les cadres génériques apparaît de manière éclatante au milieu du XVIII' siècle, à l'époque où le

1. «[...] C'est un moment extraordinaire même dans un procès comme celui-ci, extraordinaire de bout en bout», Carlo Ginzburg, op. cit., p. 89.

2. Denis Diderot, Réfutation d'Helvétius, dans Euvres, t. XI, Paris, CFL, p. 521-522. 
comédien anglais David Garrick fait son entrée en scène. Garrick n'est pas jugé hors du commun parce qu'il mêle le tragique et le comique au sein d'une même représentation - il s'en garde, et reste conforme au partage prescrit par les bienséances. Bien plutôt, c'est parce qu'il parvient à jouer avec une égale réussite dans l'un et l'autre genre, parfois au cours d'une même soirée. Pour le Français Noverre en 1765, il est bel et bien un «homme extraordinaire, qui fut tout à la fois le Protée, l'Ésope, et le Roscius de son siècle ${ }^{1} »$. Alors que la spécialisation était de mise pour tous les acteurs, associés à un emploi particulier, Garrick, grâce à son pouvoir de métamorphose qui l'assimile au dieu Protée, fait se rejoindre en un seul homme la tradition comique (Ésope) et la tradition rhétorique à l'origine du jeu tragique (Roscius, donné en exemple par Cicéron). Aux yeux de Noverre en effet, Garrick jouit d'un caractère double, à la fois français et anglais, ce qui explique qu'il soit «alternativement gai et enjoué comme un Français, sérieux et sombre comme un Anglais ${ }^{2} »$. Le jeu de Garrick redonne vie à l'imitation de la nature au fondement de la déclamation française, qui s'est progressivement sclérosée en fondant ses effets sur la répétition de codes vidés de leur sens: il relève la gageure d'associer la vivacité de l'action anglaise à l'élégante décence française. Dès lors, Garrick apparaît comme un comédien fondamentalement composite, qui fait école justement parce qu'il est à cheval sur plusieurs domaines: les genres, les traditions et les pays. À lui seul, il incarne cet idéal du juste milieu entre les extrêmes, si fréquemment invoqué dans les écrits de l'époque, qui reconfigure librement des séries.

\section{SÉRIES}

Combinaison inédite de séries, tel est bien le sens de l'intrigue ${ }^{3}$ narrée par Alain Corbin dans Le Village des cannibales ${ }^{4}$. Dans le contexte trouble des premières défaites contre l'Allemagne en août 1870, des paysans de Hautefaye, en Dordogne, supplicient un noble en s'adonnant à des atrocités inouïes, pour le châtier d'avoir crié «Vive la République»,

1. Lettre à Voltaire, 18 mars 1765, dans [Murphy], Vie de David Garrick, p. 125.

2. $2^{\text {e }}$ lettre, dans [Murphy], Vie..., p. 167.

3. Voir Paul Veyne, Comment on écrit l'histoire, Paris, Seuil, 1971.

4. Alain Corbin, Le Village des cannibales, Paris, Aubier, 1990. 
alors que, le soir même, les tortionnaires se glorifient d'avoir «rôti» un Prussien.

Pour expliquer l'explosion d'une mise à mort sanguinaire, unanimement incomprise et dénoncée comme monstruosité par les témoins du procès des «cannibales», Alain Corbin entremêle une histoire des sensibilités indexée à une anthropologie de la violence et une histoire des modalités d'expression politique dans le monde paysan. Il élabore un récit en plusieurs strates, correspondant chacune à un contexte, à un point de vue différent et donc à une série-intrigue différente. Corbin débute par quatre séries rendant compte de la «cohérence des sentiments» de la masse paysanne. Ces récits autonomes montrent comment s'emboîtent des haines a priori incompatibles. Ils retracent la genèse des détestations antinobiliaire, anticléricale et antirépublicaine selon différentes trames que cimente un récit de l'attachement des paysans à l'empereur. Ensuite, Corbin change de focale pour s'enraciner dans le contexte immédiat du massacre. Après avoir analysé les cheminements des rumeurs et la transmission des angoisses propres aux «grandes peurs» qui plombent l'atmosphère de Hautefaye, il en revient au village même qui, ce mémorable 16 août 1870, imbrique deux temporalités festives, celle de la foire et celle de l'Assomption. Troisième acte, le compte rendu minutieux du massacre haché en séquences, éclairées par une histoire anthropologique de la violence qui place en son centre le mécanisme victimaire restitué par René Girard ${ }^{1}$. Enfin, dans un ultime récit choral, l'historien analyse le décalage, l'anachronisme que constitue cet épisode en élargissant le contexte spatial (les paysans du microcosme de Hautefaye se voient jugés sur la scène parisienne) et temporel. Cette fois, Corbin revisite la polysémie du massacre en partant de sa théâtralité eschatologique lors des guerres de religion, dans le cadre d'une histoire des sensibilités : 1792 signerait le passage du massacre cathartique au massacre monstrueux. L'histoire des modalités d'expression du politique, propres au monde paysan qui insère Hautefaye dans la geste des fureurs paysannes, explique le surgissement du drame dans un second Empire déliquescent qui ne peut plus y voir qu'un scandale terrifiant. Dans cette ultime série, l'épisode de Hautefaye crée une rupture.

Or la discontinuité n'est qu'apparente. Elle ne vaut que pour cette dernière série qui constitue l'extraordinaire de Hautefaye en anachro-

1. René Girard, Le Bouc-émissaire, Paris, Biblio Essai, 1994. 
nisme. Nul étonnement. L'anachronisme est une discordance des temps qui étonne parce qu'elle détonne. Par sa seule présence, l'anachronisme dévoile une possible coexistence de temps différents dans le sein d'une même époque. Corbin le qualifie de «monadnock», témoin d'un passé géologique resté visible dans un milieu désertique, et qui défie la cohérence paysagère par le télescopage insolite qu'il provoque. Ce sentiment de rupture repose sur l'illusion qu'une époque renvoie à une temporalité homogène. Or, coexistent des temporalités différentes intrinsèques aux phénomènes qui s'articulent parfois de façon problématique. Des diachronies se tapissent sans cesse sous une synchronie apparente. Plus que d'anachronisme, et pour échapper à une lecture idéologique instaurant un rapport de forces impliquant une condamnation, il convient de travailler sur l'écart et de parler d'anachronie. Car, si l'on remplace la conception du temps historique linéaire et irréversible par celle de durée où le «présent est un passé qui s'actualise ${ }^{1}$ », complexe et imprévisible, si l'on considère l'action d'un acteur ou d'un groupe comme l'appropriation d'un passé que traduit l'actualisation de l'ensemble des ressources disponibles (culturelles, sociales) en fonction d'une circonstance donnée, on prend en considération, à chaque chagmement de contexte, l'infini des combinaisons possibles, la capacité perpétuelle d'invention des acteurs tout en intégrant les éventuels décalages et diachronies visibles. De la sorte, on ne cessera pas de s'étonner de la violence du massacre de Hautefaye, mais on ne le pensera plus comme une rupture, simplement comme une combinaison de séries mises à nu par un événement; et on admettra sans peine, sans le condamner, sa survivance dans une France où le rituel sacrificiel convoqué a perdu son sens sacré pour ne plus exprimer que le scandale d'une cruauté monstrueuse.

Mais l'extraordinaire historique ne réside pas simplement dans une combinaison sérielle inédite. Il peut résulter d'un faisceau de séries imprévisibles mais qu'on peut reconstruire après coup, dont la convergence, perçue par un regard extérieur comme un éblouissement, entraîne éventuellement un changement de configuration de l'ordinaire à plus ou moins long terme. De telles séries qui ne préexistaient pas à cet extraordinaire, et qui étaient donc virtuelles, s'actualisent dans certaines circonstances, selon un processus intelligible mais non nécessaire - contingent - pour instaurer un nouvel ordre.

1. Bernard Lepetit, «Le présent de l'histoire», Carnet de croquis..., op. cit. 
On peut identifier l'expression de ce phénomène dans l'analyse que fait José Javier Ruiz Ibañez du don de Cambrai à Philippe II, en 1595, par l'assemblée municipale, au détriment de l'archevêque et ancien seigneur de la ville. En acceptant cette offre, le souverain Habsbourg semble légitimer le procédé insolite du consensus populi. Le peuple jouirait-il d'une capacité de décision en matière de souveraineté? Bénéficierait-il d'un droit de résistance contre un prince établi ? Voilà de quoi sabrer les piliers de la domination monarchique et fournir des arguments à l'archevêque pour récupérer la ville en cas de revirement de la volonté populaire ${ }^{1}$.

Cherchant à éclaircir cet extraordinaire, Ruiz Ibañez dégage la notion de «possibilisme» grâce à laquelle il pense la coexistence de plusieurs scénarios qui peuvent ou non s'actualiser à plus ou moins long terme et passer d'un état de possible virtuel à un état de possible effectif. Il rappelle d'abord les antécédents qui rendent possible ici un consensus populi et dessinent une première série: en 1580, les Cortès (assemblées représentatives) de Tomar avait reconnu le roi d'Espagne comme roi du Portugal; en 1593, Philippe avait octroyé aux états généraux un statut d'interlocuteur légitime, exploitant les guerres civiles françaises pour obtenir la couronne. Dans ces deux cas, on avait accordé à une assemblée représentant le populus un rôle décisif dans le choix et l'approbation de son souverain. Dans une seconde série, l'historien rappelle que la conception médiévale pactiste où le pouvoir était transmis de Dieu au souverain, par l'intermédiaire du peuple, soulignait l'importance du résidu populaire dans la légitimation du pouvoir de la monarchie et montrait que cette conception était bien présente dans l'esprit des habitants de Cambrai. Il combine ce paramètre avec la volonté de se débarrasser de la tutelle de l'archevêque, qui était le seigneur de la ville. Puis, Ruiz Ibañez détermine le faisceau des justifications de l'appropriation de Cambrai par Philippe. Or ce faisceau renvoie aux séries divergentes qu'il a établies dans un premier temps, et que le contexte de la guerre permet de concrétiser, d'actualiser.

Pour la ville, le don avait valeur d'acte de vassalité comme expression du droit électif. Le roi, pour sa part, n'y voyait que la confirmation d'une propriété de guerre et non la reconnaissance d'une capacité élec-

1. Ruiz Ibañez et José Javier, Felipe II y Cambrai : el consenso del pueblo. La soberanía entre la práctica y la teoría política (1595-1597), Madrid, Colección histórica, 1999. 
torale populaire. Une flexibilité maximale de l'interprétation pouvait aussi conduire à admettre une décision du peuple en matière de souveraineté. La multiplicité des interprétations, permettant ici d'éviter de trancher explicitement, fonde la possibilité de l'événement. L'épisode de Cambrai aurait pu ouvrir la voie à l'affirmation d'une souveraineté populaire, et conduire à une reconfiguration du champ politique. Ce n'est pas le cas. Mais à cela la raison est claire: la pratique politique postérieure a rejeté dans l'ombre la dimension pactiste du don de Cambrai. La ville fut ainsi maintenue sous tutelle, paralysant l'actualisation d'une véritable révolution dont la possibilité était pourtant comprise dans la coexistence des séries virtuellement capable d'assurer son avènement.

\section{LE PEUPLE SANS GÉNIE?}

À l'époque moderne, la norme nobiliaire exige une tentative constante de demeurer au-dessus du commun, entendu comme caractéristique du tiers état. C'est Rodrigue triomphant de la nature commune (son amour) au nom des valeurs sociales propres à la noblesse. Au XIX ${ }^{\mathrm{e}}$ siècle, il n'y a théoriquement plus que de l'ordinaire: tous égaux. Dans un monde postrévolutionnaire où l'appartenance d'ordre ne suffit plus à dire les qualités, où chacun doit être jugé pour ce qu'il est personnellement, mais où les structures collectives visant à aider l'individu sont faibles, la réussite ne devait-elle pas être pensée comme le produit d'une lutte triomphante de l'individu démocratique contre les forces pesantes de la société, ou comme le fruit du génie, impossible à insérer dans la série causale d'un mécanisme social spécifique? Soit. Mais le génie, qui surgit comme l'extraordinaire du monde postrévolutionnaire, serait-il pour autant hors d'atteinte de la compréhension scientifique?

Dans son interprétation du phénomène Mozart, Norbert Elias refuse de poser le musicien à part, hors de toute série rationnelle et dans un monde où il définirait seul ses règles. Il choisit d'en interpréter l'existence à l'intersection de plusieurs séries et explique la naissance de ce génie comme une manière de résoudre la contradiction entre deux univers de normes, celui de la cour et celui de la bourgeoisie ${ }^{1}$, celui du XVIII ${ }^{\mathrm{e}}$ siècle et celui du XIX ${ }^{\mathrm{e}}$ siècle:

1. Norbert Elias, Mozart, sociologie d'un génie, Le Seuil, 1991. 


\section{Penser par extraordinaire}

À y regarder de près, écrit Elias, [...] les grandes créations naissent toujours de la dynamique conflictuelle entre les normes des anciennes couches dominantes sur le déclin et celle des nouvelles couches montantes ${ }^{1}$.

Cette analyse sociologique permet de préserver l'idée d'un Mozart individu exceptionnel, mais se refuse à toute naturalisation, à toute idée d'un génie hors du temps dont le destin n'aurait pas été «profondément influencé par sa situation sociale» et sa «dépendance [...] à l'égard de l'aristocratie de la cour ${ }^{2} »$.

Au regard de cette démarche, l'absence quasi-totale de génies reconnus dans le monde populaire apparaît comme un paradoxe. Pourquoi l'extraordinaire populaire, au lieu d'être compris comme invention d'une norme nouvelle à la croisée de plusieurs autres, est-il renvoyé à l'absurde ou à la folie ? La tendance à renvoyer le populaire à une monomanie, à un univers clos et simple ou à une norme unique est courante. Peut-être signale-t-elle notre difficulté à penser que des individus populaires puissent obéir à des normes qui ne sont pas les «leurs», celles auxquelles on aimerait les voir assignés? Peut-être signale-t-elle notre refus de voir le populaire subvertir les normes, pour le laisser à la clôture rassurante de l'univers qu'on lui a assigné 3 ? S'il est difficile de regarder les ouvrierspoètes étudiés par Jacques Rancière, n'est-ce pas précisément qu'ils peuvent brouiller les normes et les frontières entre les séries ordonnées par l'historien ou le sociologue? Ils sont des ouvriers parlant comme des bourgeois.

Prendre la mesure non pas du génie, mais de l'extraordinaire en histoire du populaire serait alors reconnaître la pluralité des logiques sousjacentes dans le monde populaire, lui rendre sa complexité au lieu de le réduire, comme souvent, à la banalité, à la pauvreté des simples. Mais ce serait aussi reconnaître les forces de domination au travail qui empêchent que les logiques dérangeantes viennent au jour. S'il peut arriver qu'un homme du peuple vers 1715 émette clairement une opinion politique, voire prône la révolution ou la nécessité d'instruire tous les artisans, s'il peut arriver que les ouvriers du XIX ${ }^{e}$ siècle soient poètes, ce que nous apprennent surtout ces cas, c'est que les logiques entrant dans la compo-

1. Ibidem, p. 18.

2. Ibidem, p. 24.

3. Voir Jacques Rancière, La Nuit des prolétaires. Archives du rêve ouvrier, Paris, Fayard, 1981. 
sition de tels phénomènes sont, pour la plupart, minoritaires, dominées. Les mettre en avant, c'est objectiver cette domination.

Ainsi, tandis que la problématique du génie renvoie à une soumission à l'ordre unique d'une nature étonnante, celle de l'extraordinaire implique la compréhension des séries multiples en conflit dans l'histoire. D'où la portée politique du «penser par extraordinaire» révélatrice des logiques majoritaires oppressives au travail dans l'histoire et des forces préservées prêtes à sourdre.

\section{HÉROS}

La pièce de théâtre de Fernando de Zárate opportunément intitulée Le noble est toujours courageux ${ }^{1}$ montre que les vertus de l'héroïsme, expression de l'excellence de l'état nobiliaire, et codifié dans un code de l'honneur auquel on ne saurait déroger sous peine de déchoir, n'a rien d'extraordinaire. L'héroïsme incarne en réalité la quintessence d'un ordre social pensé comme supérieur. N'est-il pas significatif que l'étonnement suscité par celui-là s'apparente à de l'admiration et non à de la perplexité ?

L'héroïsme ne pose aucune injonction logique, pas plus qu'il ne remet en cause les cadres du raisonnement. Luc Boltanski et Laurent Thévenot ont ainsi réfléchi au rôle structurant de la grandeur dans l'organisation des catégories par lesquelles une société se pense ${ }^{2}$. Prise dans cette logique, la grandeur qui permet d'identifier des héros suscitant l'admiration au sein d'une société donnée est une notion évolutive qui peut refléter l'ordinaire d'un certain groupe social. Le contenu de l'héroïsme varie selon les ensembles épistémiques et correspond tantôt à un principe de hiérarchie, au jugement de l'opinion, à l'incarnation de valeurs communes octroyant une représentativité civique et politique désignant les grands hommes, ou à la performance.

En outre, lorsque l'on tente de faire du héros un objet des sciences humaines, en bannissant toute émotion du discours et du processus d'appré-

\footnotetext{
1. Fernando Zárate y Castronovo, El noble es siempre valiente, manuscrit autographe daté de 1660 , d'après La Barrera, Catálogo del teatro antiguo español.

2. Luc Boltanski et Laurent Thévenot, De la justification. Les économies de la grandeur, Paris, Gallimard, 1991. Voir en particulier le chapitre 6: «Présentation des mondes».
} 
hension, on débouche paradoxalement sur une quête du représentatif, sous-tendue par le postulat implicite d'un lien indéfectible entre l'individuel et l'ordre général ${ }^{1}$. Le héros devient cette entité désincarnée qui «fait» son époque, inséré dans une trajectoire impeccablement linéaire, qui structure un récit où alternent des phases où il reflète son temps et d'autres où il le construit ${ }^{2}$. Tantôt, on oublie le héros, qui se réduit à un prétexte pour raconter une époque, tantôt il a valeur d'échantillon traduisant un contexte, et ne présente plus qu'un intérêt illustratif.

L'échec d'une quête de l'extraordinaire singularité du héros achoppe sur un problème épistémologique: la démarche, dans sa volonté d'appréhension scientifique, a évacué ce qui résiste à la classification et rend le héros unique. Comment rendre compte de la singularité et la contingence d'une trajectoire qui apprend du nouveau au chercheur, en louvoyant entre deux écueils: la réduction de cette trajectoire à un substrat qui favorise l'application d'un savoir préexistant, et son asservissement à un rôle illustratif? Dans cette perspective, le terme d'exception sied sans doute mieux au héros que le qualificatif d'extraordinaire. En tant qu'homme exceptionnel, le héros ne défie certes pas la norme, mais celle-ci ne le vampirise pas non plus. Il ne s'agit plus d'extraire du non conforme, ou de l'étrange, de la matrice que présente l'ordinaire, mais de penser par l'individualité. Le dispositif implicite n'oppose plus le particulier au général et abandonne le paradigme quantitatif pour se diffracter en des trajectoires uniques. On se rapproche de façon asymptotique du concept d'«exceptionnel normal» forgé par Grendi, à la lumière des travaux de l'anthropologue Fredrik Barth ${ }^{3}$, sans qu'on puisse pourtant s'en réclamer. En effet, ce qui importe ici n'est pas l'établissement d'un modèle génératif qui circonscrive un espace couvert par des variations traduisant des dynamiques d'interaction entre des individus. Ce qui importe, c'est une singularité irréductible mise en acte. Le héros n'apparaît donc plus comme le siège de vertus hérö̈ques, mais comme le sujet

\footnotetext{
1. Sur la question de la biographie, voir Sabrina Loriga, «La biographie comme problème», dans Jeux d'échelles. La micro-analyse à l'expérience, Paris, Éditions de l'EHESS/Le Seuil, 1996, p. 209-231.

2. Thomas Carlyle, chantre de la biographie héroïque, conscient du principe d'individualité et refusant de réduire l'homme à la résultante des forces qui traversent une époque, échoue pourtant à échapper aux contradictions de cette quadrature du cercle. Voir Thomas Carlyle, On Heroes, Hero-Worship, and the Heroic History, Londres, Oxford University Press, 1974.

3. Paul-André Rosental, «Construire le "macro" par le "micro": Fredrik Barth et la microstoria», dans Jeux d'échelles. La micro-analyse à l'expérience, op. cit., p. 141-59.
} 
principal d'une intrigue. Plus que le terme d'exception, s'impose alors celui de singularité ${ }^{1}$, qui fait se rejoindre le héros du champ historique et celui du champ littéraire: héros ordinaires, dignes d'occuper le centre d'un récit construit, héros quotidiens, héros inconnus... ou sabotiers analphabètes de la Basse-Frêne, tel Louis-François Pinagot, dont Alain Corbin s'est essayé à traiter le cas en revendiquant, dans une certaine mesure, la négation de l'héroïsme².

\section{MODÈLE}

À partir de la reconnaissance du pouvoir créateur de l'imagination, les productions d'un génie comme Shakespeare ouvrent la voie à la création de genres nouveaux, cela par le biais d'une redéfinition de la notion de modèle. Depuis la Renaissance, les auteurs sont en effet invités à fonder leur inventio sur l'imitation des œuvres des Anciens, qui seraient parvenus à montrer la belle nature en sélectionnant et en rassemblant les plus beaux traits de la nature originelle, auxquels eux seuls ils auraient eu accès: les auteurs qui les suivent ne doivent pas s'inspirer directement de la nature, mais des œuvres de ceux qui ont su réaliser le modèle idéal. Au prix d'un renversement de perspective, l'écrivain et historien CharlesJean-François Hénault (1685-1770) fait des œuvres de Shakespeare une source d'inspiration, justement parce qu'elles dérogent apparemment à tout ordre: «De même que les monstres sont utiles pour l'anatomie, les tragédies de Shakespeare m'ont fait concevoir des usages dramatiques auxquels je n'aurais jamais pensé sans eux ${ }^{3} »$, écrit-il en 1747. Somme toute, le fait que Shakespeare ne se conforme pas à l'ordre entériné par l'imitation des modèles permet d'envisager d'une manière nouvelle leur utilisation: c'est, non pas la lettre, mais l'esprit, le processus de création des Anciens, et partant, celui de Shakespeare, directement inspiré de la nature, qu'il s'agit d'imiter. De fait, les classiques n'auraient pas compris que les œuvres des Anciens n'appelaient pas une imitation littérale,

\footnotetext{
1. Le terme d'exception ne prend son sens que par son jeu avec celui de norme. Mais dans chacun des cas, c'est bien d'une singularité qu'il s'agit.

2. Alain Corbin, Le Monde retrouvé de Louis-François Pinagot, sur les traces d'un inconnu (17981876), Paris, Flammarion, 1998.

3. Président Hénault, François II, préface, 1747.
} 
autrement dit une représentation de l'histoire de l'Antiquité. Au contraire, les tragédies historiques de Shakespeare, monstrueuses au regard du paradigme aristotélicien, constitueraient un exemple concret prouvant qu'il est possible d'emprunter la fable d'une tragédie au passé de la nation: en subvertissant la définition de l'imitation des modèles à partir d'un cas monstrueux, le président Hénault élabore François II, l'un des premiers spécimens du drame national. Le nouveau genre dramatique jouira d'une grande faveur dans la seconde moitié du XVIII ${ }^{\mathrm{e}}$ siècle, chez Louis-Sébastien Mercier et Marie-Joseph Chénier notamment.

\section{RHÉTORIQUE DU MONSTRUEUX}

Tout autant qu'il adresse le regard, le monstre est l'incarnation du mal et symbolise la désagrégation. Cantonnée à un registre moral, la qualification de monstre condamne ainsi celui qui subvertit l'ordre de façon délibérée et qui le menace précisément parce qu'il en fait partie; elle se fait aussi l'écho de la peur qui naît de la perspective de l'inconnu indissociable du désordre. Aux époques médiévale et moderne, les correspondances analogiques tissées entre macrocosme et microcosme, corps physique, corps politique et corps mystique, expliquent que les distorsions du corps du monstre, ses excroissances et ses hybridations manifestent un anticosmos. Préfigurant une apocalypse, le monstre surgit dans des atmosphères eschatologiques et devient l'instrument d'un châtiment surnaturel. Expression imagée d'un désarroi qui cherche à transcrire l'irreprésentable, c'est aussi spontanément que l'on recourt à sa figure pour tenter de dire l'indicible, le désordre et la peur qui en découle. Ainsi, le monstre comme signe de l'irruption de l'inhumanité ou de la barbarie qui laissent l'observateur démuni n'a en soi rien d'extraordinaire. De fait, l'existence effective des monstres n'a jamais réellement importé, et d'aucuns ont eu beau jeu de résoudre la contradiction en affirmant que l'imagination renfermait le pouvoir de créer des monstres - justement pas au sens où l'entendait Goya dans un de ses célèbres «Caprichos», $L e$ sommeil de la raison engendre des monstres, qui faisait du monstre le produit de l'imaginaire débridé du rêve, sans existence effective. N'attribuait-on pas jadis aux femmes enceintes le pouvoir d'accoucher de monstres, pour avoir eu l'imagination peuplée de pensées malsaines ou pour 
avoir assisté à des scènes immorales pendant leur grossesse ${ }^{1}$ ? Mais la tentative ne fait que pointer le lien indéfectible entre le monstre et l'imagination. Si le monstre est imaginaire, alors il a force agissante avant tout rhétorique. Lors des guerres de religion, les libelles et textes polémiques diffusés assimilent ainsi l'ennemi à un animal monstrueux ${ }^{2}$. Plus tard, les occasionnels, ces imprimés qui paraissaient de façon ponctuelle et qui fleurissent au XVII ${ }^{\mathrm{e}}$ siècle, brandissent la figure du monstre pour édifier ou stigmatiser, dans le cadre d'anecdotes le mettant en scène à la manière d'exempla. De nos jours enfin, dans un monde présumé désenchanté où le merveilleux semble raréfié, le surgissement de l'extraordinaire entraîne une avalanche d'images évoquant le monstre. Le monstre (supposé réel ou métaphorique) serait ici le produit ordinaire de l'imagination pour exprimer l'effroi face à une situation extraordinaire.

La relégation du monstre dans l'imaginaire évacue donc ce qu'il pouvait charrier intrinsèquement de négatif. Pourtant, on ne saurait ignorer la prégnance de la dimension morale sous-jacente au thème de la monstruosité. C'est que le monstre ne renvoie pas seulement à un écart par rapport à un ordre auquel il échapperait, mais à sa transgression. Les hybrides appellent une condamnation en ce qu'ils sont le produit d'unions contrenature entre les espèces et les règnes. Dans l'Orient antique, la croyance dans la continuité des espèces que traduisaient les phénomènes de métamorphoses ou de métempsychoses interdisait de qualifier de monstruosité l'imbrication des règnes. En revanche, dès lors qu'on classe les espèces et qu'on établit un ordre à la manière d'Aristote, la négation des normes crée des monstres. Une analyse de la notion de monstre ne doit donc pas raisonner en termes de causalité mais de responsabilité. Rien n'est monstrueux dans la nature, la monstruosité étant le fait de l'humain.

Au Moyen Âge, notamment, la figure de l'altérité a souvent pris la forme d'un fabuleux incarné par les monstres. Géants, cynocéphales, cyclopes peuplent les récits de voyageurs de l'époque médiévale. Si l'on en croit les périodisations de certains historiens, les gens du Moyen Âge (par contraste avec ceux de la Renaissance) ne savaient pas regarder: ils étaient toujours prêts à écouter et à croire ce qu'on leur disait ${ }^{3}$, tandis que

\footnotetext{
1. Jacques Blondel, Dissertation physique sur la force de l'imagination des femmes enceintes sur le fotus, Paris, 1727.

2. Denis Crouzet, Les Guerriers de Dieu. La violence au temps des troubles de religion, Seyssel, Champ Vallon, 1990, p. 262-269.

3. Jacques Le Goff, Pour un autre moyen âge, Paris, Gallimard, 1977, p. 283.
} 


\section{Penser par extraordinaire}

les hommes de lettres d'alors étaient plus prompts à citer qu'à observer ${ }^{1}$. Dès lors on peut comprendre la grande place qu'occupe l'imaginaire dans les récits de voyage. Néanmoins, cette vision doit être nuancée. Tout d'abord, les premières grandes explorations prennent place dès le milieu du XIII ${ }^{\text {e }}$ siècle, notamment vers l'Orient, et ne sont pas restés confidentielles. Outre que des récits ont circulé rapidement dans toute l'Europe, on tente très vite de coudre ensemble les savoirs d'une géographie humaine fondée sur les témoignages oculaires et non sur les redites des auctoritates, par le biais de compilations comme celle de Mandeville (1356). Christiane Deluz a montré que loin d'être un tissu de fabulations, elles contenaient l'élaboration d'un savoir qui reposait sur une rhétorique parente, pour ne pas dire similaire, à celle du discours scientifique $^{2}$. Ce savoir s'appuie sur les même procédés de «débrayage actantiel» et «temporel», c'est-à-dire sur l'affirmation d'une vérité ou d'une logique supérieure qui dépasse l'énonciateur du discours, et sur la mise en avant d'un dépassement du «maintenant» et de l'anecdote vers le «permanent». Ces compilations annoncent la rationalisation des récits de voyage à l'époque moderne.

À la suite d'Edmund Leach ${ }^{3}$, on observera aussi que les expériences oculaires directes des grands voyageurs ne donnaient généralement pas lieu à des affabulations. Ces grands voyageurs pouvaient être de remarquables observateurs. La plupart des faits qu'ils rapportent sont véridiques, ce qui n'implique pas forcément qu'on les croyait à leur retour. Ainsi le récit de Marco Polo est passé bien longtemps pour une fable, bien qu'il soit très souvent exact. Très tôt, les voyageurs ne décrivent pas l'expérience de l'altérité vécue en usant d'une rhétorique de la monstruosité. En revanche, lorsqu'ils passent à l'observation rapportée, ils se laissent aller à un imaginaire «fantastique». Le monstre n'est alors pas celui que l'on voit mais celui dont on entend la rumeur. Comment expliquer ce recours rhétorique au monstrueux? On pourrait ici avancer une explication en terme de cadre cognitif: à supposer que l'appréhension de la réalité demeure toujours médiatisée par les images et les catégories perceptives de la culture 4 , l'expérience de «ce qui est» est modalisée par «ce qui a

\footnotetext{
1. Jean Favier, Les Grandes découvertes: d'Alexandre à Magellan, Paris, Fayard, 1991, p. 249

2. Christiane Deluz, Le Livre de Jean de Mandeville, une géographie au XIVe siècle, Louvain-la-Neuve, Université catholique de Louvain, 1988.

3. Edmund Leach, L'Unité de l'Homme, Paris, Gallimard, 1980, p. 369.

4. Kilani Mondher, L'Invention de l'autre, Lausanne, Payot, 1994, p. 75.
} 
déjà été dit $^{1} \gg$. On sait aussi la puissance d'anticipation que ce cadre perceptif procure: on déduit avant d'avoir vu. Ainsi, Kilani montre comment Christophe Colomb décrit un peuple nu alors qu'il n'en a vu qu'une jeune fille. Il ne décrit pas ce qu'il voit mais ce qu'il s'attend à voir, même s'il se situe dans une perspective de description ${ }^{2}$. Il en va presque de même pour les monstres du Moyen Âge, à la différence près qu'il n'existe pas de «ce qui est». En effet, cette expérience de l'extraordinaire n'est pas expérimentée mais rapportée. Dès lors, pour la décrire, il ne reste plus que «ce qui a déjà été dit». Devant cet extraordinaire non expérimenté, les voyageurs mobilisent des catégories cognitives partagées qu'offrait justement la mythologie et qui permettent de le rendre intelligible. Cet Autre monstrueux recule avec les explorations mais surtout parce qu'un savoir cumulatif et transmissible se met en place pendant l'époque moderne, et qu'il s'est déplacé de nos jours dans l'espace extra-terrestre, avec la science-fiction, dans la figure de l'alien.

\section{INTERPÉTER L'INVISIBLE}

Avant les années 1730, Shakespeare, dont les œuvres sont pourtant publiées pour la première fois dès 1623 , reste quasiment inconnu des Français, à quelques exceptions près ${ }^{3}$. D'autres pièces du théâtre anglais sont pourtant traduites dès le début du XVIII ${ }^{\mathrm{e}}$ siècle ${ }^{4}$. L'explique aisément leur proximité plus grande avec la dramaturgie classique, qu'elles ne heurtent pas de plein fouet comme le font les drames shakespeariens. Ce n'est que bien plus tard qu'on commence à diffuser Shakespeare, au moment où la mise en cause de la froideur de la tragédie classique s'est muée en lieu commun, au moment où l'œuvre du dramaturge anglais vient conforter la critique et le public dans ses attentes et ses opinions. L'immense succès du jeu du comédien David Garrick est quant à lui attribué par les contemporains à son caractère fondamentalement hybride :

\footnotetext{
1. Kilani Mondher, L'Invention de l'autre, Lausanne, Payot, 1994, p. 76.

2. Ibidem, p. 65-66.

3. Madeleine Horn-Monval, Les Traductions françaises de Shakespeare, Paris, CNRS, 1963, p. 6.

4. De nombreuses traductions du théâtre anglais paraissent à partir de 1700, et sont souvent rééditées: en 1700, sont traduits The Provoked Wife de Wycherley, Cato d'Addison (par Boyer), The Drummer d'Addison (par Destouches). The Merchant of London de Lillo et The Devil de Colley sont traduits en 1731 .
} 
il se rapproche du comportement quotidien, tout en restant conforme aux bienséances chères aux classiques, gageure jugée sans égale. En effet, le jeu de Garrick est en réalité accepté par le public justement parce que celui-ci trouve son plaisir dans la reconnaissance de l'ordre et de sa mise en cause, et cela malgré le fait qu'il soit appréhendé à des fins stratégiques comme un ferment de bouleversement d'un ordre factice. Garrick ne montre pas la nature brute sur la scène, mais en propose une recomposition qui emprunte très largement à l'ordinaire classique. Pour être lisible par le spectateur, son jeu muet est composé d'attitudes, de pauses et de poses qui empruntent à la représentation traditionnelle des passions codifiée par Le Brun à la fin du XVII siècle. Les observateurs soulignent combien ses interprétations sont nobles et respectent les bienséances, lesquelles empruntent aux règles de la civilité et sont donc aux antipodes de la «barbarie» shakespearienne. Il est donc peu surprenant que le jeu muet de Garrick, pourtant fort éloigné de la tradition déclamatoire française, ait été si bien reçu lors des escapades du comédien dans les salons parisiens. Il fit particulièrement fureur au salon dans la scène où Macbeth, sur le point d'aller assassiner le roi Duncan, voit un poignard tournoyer dans les airs. Par sa pantomime muette, associée à l'expression stupéfiante de rapides transitions d'une passion à l'autre, le comédien anglais sortait en effet indiscutablement de l'ordinaire, sans pour autant heurter celui-ci de plein fouet. L'extraordinaire shakespearien rejoint alors, par le biais du comédien, la conception classique de ce qui est acceptable sur la scène.

En effet, selon l'esthétique classique, l'extraordinaire est évacué s'il reste à l'état brut, ou s'il est mis en avant comme extraordinaire; au contraire, il est accepté s'il est adapté au goût du public, comme le personnage de Néron, que Racine modifie pour le rendre plus conforme aux bienséances ${ }^{1}$. Le Chef-d'œuvre inconnu de Balzac illustre, à la façon d'une parabole, le rôle d'un tel intermédiaire qui seul rend visible l'extraordinaire et le génie. Le personnage de Frenhofer apparaît comme un artiste qui communie avec le «divin», empli de visions sublimes. Pour Nicolas Poussin, mis en scène par le romancier, il est «l'Art lui-même; l'art avec ses secrets, ses fougues et ses rêveries ${ }^{2} \gg$. Or, il ne peut ni trans-

1. Voir George Forestier, Introduction à l'analyse des textes classiques. Éléments de rhétorique et de poétique du XVII siècle, Paris, Nathan, 1993, p. 13.

2. Honoré de Balzac, Le Chef-d'œuvre inconnu, Paris, Garnier-Flammarion, 1981, p. 57. 


\section{Labyrinthe, $n^{\circ} 26$}

mettre, ni rendre perceptibles aux autres les fulgurances qui l'habitent, car le geste du peintre ne suit pas. La traduction de cet extraordinaire se heurte à l'impossibilité de sa mise en œuvre effective. Prisonnier de son esprit, l'extraordinaire de Frenhofer ne parvient pas à se résoudre à une descente dans la matière. Lorsque le peintre s'y essaie, il ne fait surgir qu'un magma qui pétrifie d'effroi le spectateur, «des couleurs confusément amassées et contenues par une multitude de lignes bizarres qui forment une muraille de peinture ${ }^{1} »$. Seul le pied parfait de la «Belle Noiseuse» stupéfie le héros, qui reste confondu devant cette présence infime de l'extraordinaire, devant ce souffle d'éternel. Prisonnier d'un informe, l'extraordinaire de Frenhofer demeure invisible. La scène finale, où Frenhofer se résout enfin à montrer sa toile, rend compte de l'échec de l'artiste sur un mode tragique:

- Ah! Ah! s'écria [Frenhofer], vous ne vous attendiez pas à tant de perfection! Vous êtes devant une femme et vous cherchez un tableau. [...] Mais elle a respiré je crois!... Ce sein, voyez? Ah! qui ne voudrait l'adorer à genoux ? Les chairs palpitent. Elle va se lever, attendez.

- Apercevez-vous quelque chose? demanda Poussin à Porbus.

- Non. Et vous?

- Rien $^{2}$.

De ce «rien», ce néant, du risque toujours à craindre que la pensée n'aperçoive pas elle-même ce qui peut-être la motive en premier - le désir de s'arracher à l'ordre commun et la tyrannie du quotidien -, naît peut-être le défi que nous avons ici tenté: rendre visible l'extraordinaire, dont la pensée ne saurait à bon compte se débarrasser, sous peine de se figer elle-même et de s'annihiler.

1. Honoré de Balzac, Le Chef-d'œuvre inconnu, Paris, Garnier-Flammarion, 1981, p. 69.

2. Ibidem. 